NBER WORKING PAPER SERIES

BOUNDS, BENEFITS, AND BAD AIR:

WELFARE IMPACTS OF POLLUTION ALERTS

\author{
Michael L. Anderson \\ Minwoo Hyun \\ Jaecheol Lee \\ Working Paper 29637 \\ http://www.nber.org/papers/w29637 \\ NATIONAL BUREAU OF ECONOMIC RESEARCH \\ 1050 Massachusetts Avenue \\ Cambridge, MA 02138 \\ January 2022
}

We appreciate the valuable comments from the participants of Environment and Resource Economics seminar at UC Berkeley and the members of Global Policy Laboratory at the same institution. We also send our gratitude to Solomon Hsiang, Joseph Shapiro, Reed Walker, Alejandro Favela Nava, Jenya Kahn-lang, and Andrew Wilson for their helpful comments. We thank Seungyoon Kim for his research assistance. The Global Policy Laboratory at University of California, Berkeley supported the purchase of access to the dataset used in this analysis. This study analyzed secondary data on human subjects under Korea National Institute for Bioethics Policy IRB P01-201811-22-008. The views expressed herein are those of the authors and do not necessarily reflect the views of the National Bureau of Economic Research.

NBER working papers are circulated for discussion and comment purposes. They have not been peer-reviewed or been subject to the review by the NBER Board of Directors that accompanies official NBER publications.

(C) 2022 by Michael L. Anderson, Minwoo Hyun, and Jaecheol Lee. All rights reserved. Short sections of text, not to exceed two paragraphs, may be quoted without explicit permission provided that full credit, including $(\odot$ notice, is given to the source. 
Bounds, Benefits, and Bad Air: Welfare Impacts of Pollution Alerts

Michael L. Anderson, Minwoo Hyun, and Jaecheol Lee

NBER Working Paper No. 29637

January 2022

JEL No. I12,I18,Q53

\begin{abstract}
$\underline{\text { ABSTRACT }}$
Though air-quality alert systems (AQAS) cover more than 1.7 billion people worldwide, there has been little welfare analysis of these systems. This paper presents a theoretical framework for deriving lower bounds on the net benefits of an AQAS and applies it to a South Korean system currently covering over 51 million people. Estimating a regression discontinuity design, we find that an alert issuance reduced youth respiratory expenditures by $30 \%$ and adult cardiovascular expenditures by $23 \%$. The overall system reduced externalized health expenditures by 28.6 million dollars during 2016-2017, with a minimum benefit-cost ratio of 7.1:1. Including dynamic impacts of alerts increases the minimum benefits (benefit-cost ratio) to 36.7 million dollars (9.2:1). Our findings imply that the AQAS generates significant net benefits and suggests that manipulation of air quality data, which has been observed in other contexts, may negatively impact social welfare.

Michael L. Anderson

Department of Agricultural and

Resource Economics

207 Giannini Hall, MC 3310

University of California, Berkeley

Berkeley, CA 94720

and NBER

mlanderson@berkeley.edu

Minwoo Hyun

Department of Economics

University of California, Santa Barbara

minwoohyun@ucsb.edu

Jaecheol Lee

University of California, Berkeley

Department of Agricultural and

Resource Economics

ferleejc@berkeley.edu
\end{abstract}




\title{
Bounds, Benefits, and Bad Air: Welfare Impacts of Pollution Alerts
}

\author{
By Michael L. Anderson, Minwoo Hyun, And Jaecheol Lee*
}

\begin{abstract}
Though air-quality alert systems (AQAS) cover more than 1.7 billion people worldwide, there has been little welfare analysis of these systems. This paper presents a theoretical framework for deriving lower bounds on the net benefits of an AQAS and applies it to a South Korean system currently covering over 51 million people. Estimating a regression discontinuity design, we find that an alert issuance reduced youth respiratory expenditures by $30 \%$ and adult cardiovascular expenditures by $23 \%$. The overall system reduced externalized health expenditures by 28.6 million dollars during 2016-2017, with a minimum benefit-cost ratio of 7.1:1. Including dynamic impacts of alerts increases the minimum benefits (benefit-cost ratio) to 36.7 million dollars (9.2:1). Our findings imply that the AQAS generates significant net benefits and suggests that manipulation of air quality data, which has been observed in other contexts, may negatively impact social welfare.
\end{abstract}

Air quality alert systems, which notify individuals of unhealthy pollution levels, are widespread throughout the world, covering over 1.7 billion people. For example, the United States (US) Environmental Protection Agency (EPA) manages the Air Quality Alert Program in the New England Area, and California air quality districts each run their own alert systems. In the United Kingdom, the Department for Environment, Food, and Rural Affairs issues pollution alerts. In Beijing, environmental authorities enacted a four-tier warning policy in 2013, expanded nationwide in 2014, and the South Korean government in 2015 launched a new air quality alert system (AQAS) as well ${ }^{1}$ These programs encourage the public to wear particulate-filtering masks, stay indoors, and reduce strenuous activities to mitigate health damages from air pollution.

Despite their increasing popularity, there has been little empirical analysis of the welfare impacts of these programs. In this work, we exploit the structure of the South Korean AQAS to estimate a regression discontinuity (RD) design using pollution measurements as the running variable. Combining economic theory with our estimates, we establish

\footnotetext{
* Lee (corresponding author): Department of Agricultural and Resource Economics, University of California, Berkeley, ferleejc@berkeley.edu. Hyun: Department of Economics, University of California, Santa Barbara, minwoohyun@ucsb.edu. Anderson: Department of Agricultural and Resource Economics, University of California, Berkeley, mlanderson@berkeley.edu.

Acknowledgements: We appreciate the valuable comments from the participants of Environment and Resource Economics seminar at UC Berkeley and the members of Global Policy Laboratory at the same institution. We also send our gratitude to Solomon Hsiang, Joseph Shapiro, Reed Walker, Alejandro Favela Nava, Jenya Kahn-lang, and Andrew Wilson for their helpful comments. We thank Seungyoon Kim for his research assistance. The Global Policy Laboratory at University of California, Berkeley supported the purchase of access to the dataset used in this analysis. This study analyzed secondary data on human subjects under Korea National Institute for Bioethics Policy IRB P01-201811-22-008.

${ }^{1}$ See Appendix Table A1 for more examples of alert systems.
} 
a lower bound on the health-related net benefits of the AQAS and an upper bound on the operating costs. This yields lower bounds on net benefits and benefit-cost ratios. Importantly, our estimates are net of the welfare loss due to avoidance behavior.

Our analysis contributes directly to two strands of literature. The first strand focuses on the health impacts of air-quality alerts. In seminal work, Neidell (2009) exploited highfrequency time-series variation to demonstrate that minors with asthma benefited from ozone alerts via a decrease Los Angeles inpatient hospital admissions due to breathing difficulties. Janke (2014) generalized these results to England and further established an effect on emergency department (ED) admissions for minors. Chen et al. (2018) found marginally significant reductions in asthma-related ED visits in Toronto due to alerts, and Mullins and Bharadwaj (2015) demonstrated that the announcement of environmental episodes in Chile could reduce mortality rates in older adults ${ }^{2}$ Recently, Aguilar-Gomez (2020) examined air quality warnings in Mexico City and found that, when combined with driving restrictions, they reduced $\mathrm{ED}$ visits ${ }^{3}$

The second emerging strand examines the effects of air pollution information on welfare measures. Ito and Zhang (2020) found that willingness-to-pay for air purifiers in China increased following the 2013 disclosure of air-quality information by the US Embassy in Beijing. Barwick et al. (2020) demonstrated that avoidance behaviors, such as air purifier sales and the timing of credit-card purchases, changed in response to the Chinese government providing real-time air quality monitoring data to the public. Gao, Song and Timmins (2021) exploited the disclosure of PM2.5 data in China to estimate the impact of relaxing information constraints on hedonic valuation.

More generally, our paper contributes to a broad literature exploring the value of information provision to the public. Previous studies found that public information provision can affect behavior in many contexts, including restaurant hygiene (Jin and Leslie, 2003), sales taxes (Chetty, Looney and Kroft, 2009), calorie labeling (Bollinger, Leslie and Sorensen, 2011), restaurant quality (Anderson and Magruder, 2012), and toxic releases (Mastromonaco, 2015). Further targeting of information may affect choices in a variety of contexts as well, from school choice to health insurance to electricity consumption (Hastings and Weinstein, 2008; Kling et al., 2012; Ito, 2014; Jessoe and Rapson, 2014). It also relates to work on establishing bounds for welfare analysis in situations with limited information (Manski et al., 1997; Finkelstein and Hendren, 2020; Kang and Vasserman, 2021).

Finally, our paper is relevant to a series of studies investigating potential efforts to manipulate pollution information for political or economic gain. Several studies found evidence that particulate matter (PM) measurements cluster right below politically-significant thresholds, compliance with which is important for government officials' promotions (Andrews, 2008, Chen et al., 2012, Ghanem and Zhang, 2014; Zou, 2021). Recent work demonstrated that reported PM concentrations increased following the automation of

\footnotetext{
${ }^{2}$ A related body of research explores who responds to air quality alerts but does not estimate effects on health outcomes (Noonan 2014, Ward and Beatty 2016, Saberian, Heyes and Rivers 2017).

${ }^{3}$ Prior to the addition of driving restrictions, the study cannot reject the null hypothesis of no effect on health outcomes.
} 
pollution monitoring (Greenstone et al. 2021). Though our analysis does not focus on manipulation of air pollution observations, our results demonstrate the potential welfare consequences of such information distortion.

We make several contributions to the literature. First, our work represents, to the best of our knowledge, the first welfare analysis of these widespread alert systems (as opposed to general air-quality monitoring). This contribution is possible because we analyze health expenditures, rather than raw visit counts or deaths, and we apply a theoretical framework that, combined with our novel health expenditure data, allow us to estimate sharp lower bounds on benefits that are net of the costs of avoidance behavior ${ }^{4}$ Second, while previous work on the benefits of alert systems exploited time-series or panel variation, we implement a RD design to study health-related outcomes 5 Finally, while most analyses of AQASs have occurred in developed countries, the pollution levels in our study region are more representative of developing and middle-income countries

\section{Background and data}

South Korea is an advanced economy that nevertheless suffers from high levels of particulate pollution. According to the Organization for Economic Cooperation and Development (OECD), South Korea's level of PM2.5 (particulates less than 2.5 micrometers in diameter) is the highest among all OECD countries. The average PM2.5 concentration level recorded in 2015 was over $30 \mu \mathrm{g} / \mathrm{m}^{3}$, while the mean of other member countries was under $15 \mu \mathrm{g} / \mathrm{m}^{3}$ Organization for Economic Cooperation and Development (2018). In response the South Korean government launched a new air quality alert system in 2015. The primary objective of the alert system is to reduce negative health effects by providing citizens with the necessary information to take precautionary measures.

Municipal governments of major cities issue the alerts. When the level of PM2.5 or PM10 exceeds a certain threshold in an alert region within a city, the local government announces a PM warning for the region (Figure 1). Citizens are encouraged to curtail outdoor activities, wear face masks, drink water, and use public transportation (Table 11). Authorities disseminate the public health warning through mass media (e.g., radio, television, and online news articles), public road signs, and wireless services (text messages and mobile applications).

Given the widespread dissemination, most people are likely informed when air quality warnings are issued. To determine whether citizens are more cognizant of air quality when alerts are issued, we analyzed internet search keywords in NAVER, a search engine accounting for $75 \%$ of all web searches in South Korea. The keywords include three

\footnotetext{
${ }^{4}$ In much of the existing literature on air quality alerts, the avoidance behavior is the object of interest, but its welfare impact cannot be quantified. Barwick et al. (2020) addresses avoidance behavior costs by estimating two specific types of avoidance behavior: air purifier purchases and outdoor shopping trips. These behaviors are less relevant to air quality alerts, since air purifiers are durable goods, and many of the benefits of alerts accrue to minors.

${ }^{5}$ The one exception we are aware of is Chen et al. (2018), which implements a RD to study health outcomes. Their study appears underpowered however, yielding a single significant $t$-statistic of exactly 2.0 across 12 outcomes tested, with no visual evidence of a break for any health outcome. Ito and Zhang (2020) exploits a spatial pollution discontinuity at the Huai River, but the study's effect of information disclosure is identified using a post-2013 indicator. Neidell (2009), Neidell [2010), and Liu, He and Lau (2018) estimate RD designs in the context of avoidance behavior.
} 
phrases: (i) air pollution alert; (ii) particulate matter; and (iii) air quality. Figure 2 indicates that searches for these keywords increased dramatically during the days on which alerts were issued 6

PM alerts are triggered based on hourly monitor readings of PM2.5 and PM10. When the new alert system began, both the 24-hour average and the 2-hour minimum values served as measurement criteria for issuing the alerts. After about a year, the Ministry of Environment (MOE) settled on the 2-hour minimum value as the sole standard. Advisories were then issued when the hourly average PM2.5 (PM10) in an alert region was over $90 \mu \mathrm{g} / \mathrm{m}^{3}\left(150 \mu \mathrm{g} / \mathrm{m}^{3}\right)$ for two consecutive hours (Table 1). These advisories remained in effect until the 1-hour level of PM2.5 (PM10) dropped below $50 \mu \mathrm{g} / \mathrm{m}^{3}$ (100 $\left.\left.\mu \mathrm{g} / \mathrm{m}^{3}\right)\right]^{7}$ We retrieved the alert information from the website of the Korea Environment Corporation (KECO). There were a total of 230 region-days or 1,427 district-days with alerts during 2016-2017, the coverage period of our health spending data ${ }^{8}$

Our health spending data cover daily per-capita spending by district in 2016 and 2017.9 The dataset comes from the National Health Insurance Service (NHIS) of South Korea, which covers the country's entire population (all individuals must join). Our data represent a 10\% random sample of insurance subscribers in seven major cities: Seoul, Busan, Daegu, Daejeon, Incheon, Gwangju, and Ulsan. Their combined population is 23 million, or $44 \%$ of the population of South Korea. Hence, our dataset includes about 2.3 million individuals. We requested separate spending measures by disease type (cardiovascular disease and respiratory disease) and age group (minors: 0-19; adults: 20-64; and older adults: 65 and older) ${ }^{10}$ The health spending data are summarized in Table 2.

Our data cover most health-care expenditures, including outpatient care (e.g. clinics and doctors' offices), hospitals (inpatient and emergency department visits), public health centers, and most prescription medications. Three features are noteworthy. First, while the data include inpatient hospital visits (i.e. overnight stays), there is often a temporal gap of a week or more between the onset of symptoms and an inpatient admission, as an inpatient hospitalization requires several rounds of referrals for all but the most acute cases. As the temporal unit of our data is daily, we exclude spending on inpatient stays from our analysis to reduce the noise in our dependent variable.

Second, we further exclude outpatient visits to tertiary hospitals in our main analysis. In the South Korean healthcare system, outpatient visits to primary (clinics) and secondary facilities (hospitals and general hospitals) typically do not require referrals, but

\footnotetext{
${ }^{6}$ This study was approved by the Institutional Review Board of the Korean National Institute for Bioethics Policy.

${ }^{7}$ When the level of PM is more extreme, governments issue a second-level warning. The PM thresholds are 180 $\mu \mathrm{g} / \mathrm{m}^{3}$ and $300 \mu \mathrm{g} / \mathrm{m}^{3}$ for PM2.5 and PM10 respectively. Our identification strategy utilizes observations around the threshold of the first-level warnings, as second-level warnings are rare. Therefore, we use terms such as advisory, alert, and warning interchangeably to indicate the first-level warning. Also note that in July 2018, the PM2.5 thresholds for issuance and cancellation were lowered to $75 \mu \mathrm{g} / \mathrm{m}^{3}$ and $35 \mu \mathrm{g} / \mathrm{m}^{3}$ respectively. This date lies outside of our analytic data set.

${ }^{8}$ Our dataset includes 73 districts across 14 alert regions.

${ }^{9}$ Due to privacy concerns, the dataset can be used only in selected data centers in South Korea. Furthermore, NHIS does not allow the sharing or publication of any type of processed data, except for summary statistics, figures, and regression results.

${ }^{10}$ Cardiovascular diseases are those in the "I" category according to the International Classification of Diseases, 10th revision (ICD-10). Respiratory diseases are those in the "J" category according to ICD-10.
} 
visits to tertiary general hospitals do 11 The referral process leads to a delay between the onset of symptoms and actual outpatient visits, and our main dependent variables accordingly exclude tertiary visit healthcare costs. Nevertheless, we test the robustness of our results to this exclusion by running regressions that include tertiary outpatient visits. The results are qualitatively similar to the main results, with coefficients and standard errors of generally comparable magnitudes.

Third, our health expenditure data consist of the sum of private copayments and public coverage. Therefore, our regression coefficients can be interpreted as changes in total health expenditures in the covered categories. It is worth noting that the out-of-pocket payment ratio ranges from $10 \%$ to $50 \%$, implying substantial coverage by the social health care system.12 Overall, the South Korean health care system subsidized $70 \%$ of the total healthcare spending on outpatient visits. We thus interpret $70 \%$ of the spending to represent external costs from the patient's perspective.

\section{Theoretical framework}

We develop a parsimonious model of an individual's avoidance behavior to motivate and interpret our empirical analysis. Consider a representative individual $i$ choosing an activity level $a$. The individual gains utility from activities that involve pollution exposure and loses utility from getting sick. Her utility function is:

$$
U_{i}\left(a_{i}, p m\right)=b_{i}\left(a_{i}\right)-s_{i}^{p v t} p_{s}\left(a_{i}, p m\right)
$$

where $b_{i}(a)$ represents the benefits of activity level $a, s_{i}^{p v t}$ represents the private costs (pecuniary and non-pecuniary) of getting sick, and $p_{s}(a, p m)$ represents the probability of getting sick given activity level $a$ and PM level $\mathrm{pm}$. One could imagine more general utility functions - e.g. $p m$ could affect $b$ as well - but to motivate our bounding exercise this model suffices.

To interpret our RD estimand, note that it compares days on which the PM level is just above the alert threshold $(p m \downarrow c)$ to those on which it is just below the alert threshold $(p m \uparrow c)$. Thus, $p m$ itself remains approximately constant near the threshold $c{ }^{13}$ but perceived PM, denoted as $p m_{i}$, changes ${ }^{14}$ Specify individual beliefs as

$$
p m_{i}=\left\{\begin{array}{lll}
p m^{a v g} & \text { if } \quad p m=p m \uparrow c \\
p m^{h i} & \text { if } \quad p m=p m \downarrow c
\end{array}\right.
$$

where $p m^{a v g}$ represents average PM conditional on being below the threshold $c$ and $p^{h i}$ represents average PM conditional on being above the threshold $c$. For our bounding exercise we assume that $p m^{h i} \approx c$, or at least that $\left|p m^{h i}-c\right|<<\left|p m^{a v g}-c\right|$. This

\footnotetext{
${ }^{11}$ Appendix Table A2 presents definitions of these types of medical institutions.

${ }^{12}$ Appendix Table $\overline{\mathrm{A} 3}$ presents details on insurance coverage by treatment location.

${ }^{13}$ Appendix Table A4 confirms that average PM levels do not change discontinuously at the RD threshold.

${ }^{14}$ In our actual data, the hourly PM level is distinct from the running variable, as the latter depends on the maximum 2-hour minimum PM level. For notational simplicity, we treat PM as the running variable in the theoretical model, but in Appendix A1 we show that our conclusions generalize to a model in which the running variable is a function of PM.
} 
representation is a reasonable approximation of our actual PM data ${ }^{15}$ More generally, the approximation only needs to be sufficiently accurate that the alerts do not cause individuals to behave less optimally than they would absent the alert's information.

Individuals maximize utility by choosing activity levels $a_{i}=\operatorname{argmax}_{a} U_{i}\left(a, p m_{i}\right)$. Then

$$
U_{i}=\left\{\begin{array}{lll}
U_{i}\left(a_{i}\left(p m^{a v g}\right), c\right) & \text { if } & p m=p m \uparrow c \\
U_{i}\left(a_{i}\left(p m^{h i}\right), c\right) & \text { if } \quad p m=p m \downarrow c
\end{array}\right.
$$

An individual's private change in utility from PM crossing the alert threshold is

$$
\begin{aligned}
& \Delta U_{i}=U_{i}\left(a_{i}\left(p m^{h i}\right), c\right)-U_{i}\left(a_{i}\left(p m^{a v g}\right), c\right)= \\
& \quad\left[b_{i}\left(a_{i}\left(p m^{h i}\right)\right)-b_{i}\left(a_{i}\left(p m^{a v g}\right)\right)\right]-s_{i}^{p v t}\left[p_{s}\left(a_{i}\left(p m^{h i}\right), c\right)-p_{s}\left(a_{i}\left(p m^{a v g}\right), c\right)\right] .
\end{aligned}
$$

Naturally $\Delta U_{i} \geq 0$ since $p m^{h i} \approx c$ and $a_{i}=\operatorname{argmax}_{a} U_{i}\left(a, p m_{i}\right)$ - i.e. more accurate PM information can only (weakly) increase the individual's utility — but accurately quantifying $\Delta U_{i}$ is challenging even with good data on $s_{i}^{p v t}$. This challenge arises because it is difficult to estimate $b_{i}\left(a_{i}\right)$, the benefits of different activities (and thus the costs of avoidance behaviors); $a_{i}$ may be high dimensional, and researchers rarely have data on all, or even most, elements of $a_{i}$.

To motivate our welfare-bounding exercise, consider the public net benefits of the individual's choices:

$$
W_{i}=U_{i}\left(a_{i}, p m\right)+E_{i}
$$

$W_{i}$, the social welfare accruing from $i$ 's choices, equals private welfare $U_{i}$ plus the externalities associated with $i$ 's choices, $E_{i}$. Then

$$
\Delta W_{i}=\Delta U_{i}+\Delta E_{i}
$$

Since $\Delta U_{i} \geq 0, \Delta E_{i}$ represents a lower bound on the social net benefits of crossing the alert threshold. By aggregating $\Delta E_{i}$ across individuals and alert days, we can estimate a lower bound on the gross social benefits of the alert system. Combined with data on the costs of the system, we can estimate lower bounds on benefit-cost ratios.

For the bound to be nontrivial, the researcher must have data on meaningful externalities associated with individuals' choices. In our context, health expenditures - the majority (about 70\%) of which are reimbursed by public funds - represent such an externality.

\footnotetext{
${ }^{15}$ For example, in our PM2.5 data, $p m^{a v g}=22.7, p m^{h i}=66.7$, and $c=57.5$. Thus $p m^{h i}$ is much closer to $c$ than $\mathrm{pm}^{\mathrm{avg}}$ is. In this context $c$ represents the average PM2.5 level when the running variable is close to the threshold, which differs from the running variable itself (see previous note).
} 


\section{Regression discontinuity design}

We employ a RD design to estimate the causal impact of PM alerts on health spending. The RD focuses on the point where the running variable (RV) exceeds a threshold at which the probability of treatment changes discontinuously. The identifying assumption is that the only difference between observations right above and below the threshold is the assignment of the treatment; other factors affecting the outcome are continuous around the threshold. It then follows that we can attribute the discontinuous change of the outcome variable to the treatment assignment.

In this paper, the issuance of advisories corresponds to the treatment, with health spending as the outcome. The running variable is the daily maximum of 2-hour minimum PM values. For example, in the case of PM2.5, an advisory occurs when the PM2.5 level is over $90 \mu \mathrm{g} / \mathrm{m}^{3}$ for two consecutive hours. Hence, when the 2-hour minimum exceeds $90 \mu \mathrm{g} / \mathrm{m}^{3}$, the alert triggers. We calculate the daily maximum of these hourly 2-hour minimum values and code the running variable at the daily level (for a given region).

As discussed in the background section, there are two pollutants that trigger the issuance of alerts, PM2.5 and PM10. Following Cattaneo et al. (2020), we calculate the daily maximum of 2-hour minimum values for PM2.5 and PM10, normalize them by their respective thresholds $\left(90 \mu \mathrm{g} / \mathrm{m}^{3}\right.$ and $\left.150 \mu \mathrm{g} / \mathrm{m}^{3}\right)$, and take the larger one as the assignment variable for the RD. By doing so, we construct one normalized assignment variable whose treatment threshold is zero (Table 1) 16 This running variable is similar to the minimum distance to the nearest threshold elucidated in Cattaneo et al. (2020).

The running variable does not perfectly determine alert issuance for (at least) two reasons. First, municipal governments also consider weather conditions when determining whether to announce an alert. Thus alerts are not issued on some days on which the normalized running variable exceeds zero. Second, the thresholds for issuance and cancellation are different. For example, suppose that an alert was issued at 2 PM Monday, when the 2-hour minimum PM2.5 exceeded $90 \mu \mathrm{g} / \mathrm{m}^{3}$. If the hourly PM2.5 level remains at $60 \mu \mathrm{g} / \mathrm{m}^{3}$ until the end of Tuesday, the alert remains in effect through Tuesday, as the PM2.5 cancellation threshold is $50 \mu \mathrm{g} / \mathrm{m}^{3}$. Nevertheless, the normalized running variable for Tuesday is -30 . For these reasons we estimate a fuzzy RD (FRD) design ${ }^{17}$

After setting a bandwidth $h$ around the threshold, we retain observations with runningvariable values falling within $h$ units of the threshold. We run the following first-stage and reduced-form regressions:

(5) Alert $_{i t}=\gamma_{1} \mathbb{1}\left(\widetilde{P M}_{i t} \geq 0\right)+\gamma_{2} \widetilde{P M}_{i t}+\gamma_{3} \widetilde{P M}_{i t} \mathbb{1}\left(\widetilde{P M}_{i t} \geq 0\right)+X_{1 i t} \theta_{1}+X_{2 t} \phi_{1}+\delta_{1 i}+u_{i t}$

\footnotetext{
${ }^{16}$ For additional details on calculating the running variable, see Appendix A2

${ }^{17} \mathrm{~A}$ concern may arise regarding the discrepancy between the thresholds of issuance and cancellation. To address this concern, we also present FRD results without these cases, and these results are comparable to our baseline FRD estimates (see Appendix Table A7).
} 
(6) $Y_{i t}=\beta_{1} \mathbb{1}\left(\widetilde{P M}_{i t} \geq 0\right)+\beta_{2} \widetilde{P M}_{i t}+\beta_{3} \widetilde{P M}_{i t} \mathbb{1}\left(\widetilde{P M}_{i t} \geq 0\right)+X_{1 i t} \theta_{2}+X_{2 t} \phi_{2}+\delta_{2 i}+\varepsilon_{i t}$

$Y_{i t}$ represents health expenditures in district $i$ on day $t, \widetilde{P M}_{i t}$ is the normalized running variable (described above), and Alert ${ }_{i t}$ is an indicator variable for an air-quality alert. $X_{1 i t}$ includes temperature and precipitation controls, $X_{2 t}$ includes year-month, day-ofweek, and holiday fixed effects, and $\delta_{i}$ are district fixed effects. While these controls are not strictly necessary for identification, they substantially improve the precision of our regressions (Cellini, Ferreira and Rothstein, 2010), ${ }^{18}$ We population weight our regressions to make the estimates more representative and further improve precision, and we cluster the standard errors by running variable value or date to account for spatial correlation in alerts and health spending across districts 19 When discussing $t$-statistics, to be conservative we default to whichever of the two standard errors is larger.

To estimate the FRD and recover the local average treatment effect (LATE), we divide $\hat{\beta}_{1}$ by $\hat{\gamma}_{1}$, yielding:

$$
\hat{\tau}_{F R D}=\frac{\hat{\beta}_{1}}{\hat{\gamma}_{1}}
$$

In practice we estimate $\hat{\tau}_{F R D}$ using two-stage least squares (2SLS). Equations (6) and (7) estimate the contemporaneous effect of an alert on health expenditures. The panel nature of our data, however, introduces additional considerations that are absent from most cross-sectional RDs. First, the asymmetry in the thresholds for issuance and cancellation ensures that many air quality alerts last for two to three consecutive days. ${ }^{20}$ One could thus conceptualize of the treatment as a single 48- to 72-hour alert. Second, the possibility of dynamic effects represents a potential violation of the stable unit treatment value assumption (SUTVA) - the treatment on day $t$ could have spillover effects on the outcome on day $t+1$.

We address this complication in two ways. First, as a robustness check, we trim the estimation sample to exclude days following a day with an air quality alert. This estimation sample yields similar results. Second, while the contemporaneous regressions (Equations (6) and (7)) appear to generate estimates that are internally valid (based on the results referenced above), they may yield an incomplete picture of the total effect of an air quality alert. In particular, they do not capture any dynamic effects of an alert that persist beyond one day. In principle these effects could shift the net impact in either direction. For example, if avoidance behavior yields health benefits beyond 24 hours, the dynamic effects could increase the net impact. Alternatively, if individuals intertem-

\footnotetext{
${ }^{18}$ The adjusted $R^{2}$ in our main outcome regressions is in the range of 0.8 to 0.9 (Tables 4 and 5 , implying that including the controls reduces the standard errors by a factor of 2 to 3 .

${ }^{19}$ Unlike typical panel data sets, serial correlation over time has little impact in our context, because the independent variable of interest, $\gamma_{1} \mathbb{1}\left(\widetilde{P M}_{i t} \geq 0\right)$, exhibits very modest time-series correlation. Clustering by district (to account for time-series correlation) generates much smaller standard errors, and two-way clustering by district and date generates standard errors that are similar in size to clustering by date.

${ }^{20}$ Out of the total 134 region-by-alert episodes, 45 episodes were single-day alerts, and the remaining 89 warnings were issued for two days or more in a row.
} 
porally substitute activities, resulting in higher than average activity on the day after an alert, then accounting for dynamic effects could decrease the net impact.

To capture dynamic effects, we estimate an alternative fuzzy RD that specifies the dependent variable as a rolling 3-day sum of health expenditures. Specifically, we estimate the reduced-form regression as:

$$
Y_{i t}^{+}=\beta_{1} \mathbb{1}\left(\widetilde{P M}_{i t} \geq 0\right)+\beta_{2} \widetilde{P M}_{i t}+\beta_{3} \widetilde{P M}_{i t} \mathbb{1}\left(\widetilde{P M}_{i t} \geq 0\right)+X_{1 i t} \theta_{2}+X_{2 t} \phi_{2}+\delta_{2 i}+\varepsilon_{i t}
$$

$Y_{i t}^{+}$represents health expenditures in district $i$ on days $t, t+1$, and $t+2$ (i.e. $Y_{i t}^{+}=$ $\left.\sum_{s=0}^{2} Y_{i t+s}\right)$. Other variables remain as defined before, and we continue to population weight the regression. Since the treatment is effectively a multi-day alert (given the asymmetry of the activation and cancellation thresholds), we also estimate a specification in which we omit treated days whose previous dates were also treated with an air quality alert. For example, if an alert was issued on January 1 and 2, January 2 is omitted, to avoid "double counting" the alert's impact when conducting policy simulations in Section $\mathrm{V}^{21}$

Before presenting the estimates we note two details about the FRD regressions. First, FRD estimates may be sensitive to the polynomial degree of the running variable. For robustness we also check results using a specification with a quadratic in the running variable 22 Second, the FRD results may be sensitive to the choice of bandwidth, $h$. To find a default bandwidth for our analysis, we follow Calonico, Cattaneo and Titiunik (2014, 2015) (CCT). The CCT criteria yield optimal bias-corrected bandwidths ranging from 17 to 22 for our dataset (Appendix Table A5), so we chose $h=20$ as the default bandwidth. To demonstrate robustness, however, we report results from bandwidth choices of 16, 20, and 24 .

\section{Results}

\section{A. Contemporaneous effects}

Figure 3 plots treatment probability by the running variable using a binned scatter plot. The figure demonstrates a large discontinuity in the probability of treatment around the RD threshold. Table 3 presents corresponding first-stage estimates of Equation (5) for three bandwidth choices $(16,20$, and 24). Crossing the RD threshold corresponds to an

\footnotetext{
${ }^{21}$ As an alternative strategy, we considered supplementing Equation 6 with lagged values of the treatment, similar to the "one-step" estimator in Cellini, Ferreira and Rothstein 2010). This specification, however, would require us to trim the sample on multiple dimensions. For example, with two lagged values of treatment we would need to trim the estimation sample based on the contemporaneous running variable and one- and two-day lags of the running variable. In practice this would reduce our estimation sample to an impractical degree. Given that almost all treatment episodes consist of two consecutive days of alerts, we chose to instead sum the outcome over several days and regard each episode of twoday treatments as a single treatment. This strategy also avoids the need to consider different sequences of treatments (Lechner 2009, Anderson 2017).

${ }^{22}$ Following the arguments in Gelman and Imbens 2019, we do not try higher-order polynomials in the running variable.
} 
approximate 60 percentage point increase in the probability of an alert. This discontinuity is robust to choice of bandwidth and highly significant in all cases, with $F$-statistics between 25 and 50. There is no significant "first-stage" effect on average PM levels (Appendix Table A4), however, which is consistent with the lack of any binding alertassociated restrictions on activity or emissions. We thus interpret our RD health effects as resulting purely from avoidance behavior rather than from reductions in ambient pollution levels.

Figure 4 plots health expenditures, converted to spending per capita in US cents, by the running variable using a binned scatter plot. The left panels present respiratory-illness expenditures, while the right panels present cardiovascular-illness expenditures. From top to bottom, the panels present expenditures for minors (under age 20), adults (age 20-64), and older adults (over age 64).

The top-left panel reveals a sharp decline in respiratory expenditures for minors at the RD threshold, and a notable, though less pronounced, decline in these expenditures for adults. In contrast there is less evidence of a decline for older adults. The topright panel reveals no change in cardiovascular expenditures for minors, likely because cardiovascular diagnoses are rare for this age group. The middle-right and bottom-right panels, however, reveal drops in cardiovascular-illness expenditures for adults and older adults at the RD threshold.

Tables 4 and 5 present corresponding reduced-form and 2SLS estimates of Equations (6) and (7) for the preferred bandwidth of $h=20$. Table 4 reports results for respiratory disease, while Table 5 reports results for cardiovascular disease. In each table, the top panel presents reduced-form estimates (i.e. estimates corresponding to Figure 4), and the bottom panel presents 2SLS estimates. Each column corresponds to a different age group: minors, adults, older adults, and all ages.

The tables confirm the patterns observed in Figure 4, In Table 4, an alert induces a highly significant decrease in respiratory-illness expenditures for minors $(t=-3.2)$. The point estimate implies a reduction of 15 cents per capita, or approximately $30 \%$ percent of mean expenditures below the RD threshold 23 For older age groups the change in respiratory-illness expenditures is insignificant at the RD threshold. Nevertheless, the overall reduction in respiratory-illness expenditures at the threshold is statistically significant $(t=-2.4)$.

In Table 5, an alert induces significant decreases in cardiovascular-illness expenditures for adults (age 20-64) and older adults ( $t=-2.9$ and $t=-2.5$ respectively). The point estimates imply reductions of 2.8 and 9.6 cents per capita respectively, or about $23 \%$ and $14 \%$ of mean expenditures below the RD threshold. For minors, there is no significant change in cardiovascular-illness expenditures at the RD threshold. The overall reduction in cardiovascular-illness expenditures at the threshold is statistically significant $(t=-3.0)$, however.

\footnotetext{
${ }^{23}$ When calculating percentage effects, we take the mean of the dependent variable when the running variable lies between -20 and 0 .
} 


\section{B. Dynamic effects}

Air pollution alerts may have lagged effects - either because an alert lasts more than one day or because avoidance behavior yields dividends over multiple days - further decreasing healthcare costs beyond the dates of alert issuance. It is also possible that the healthcare costs rebound, attenuating the magnitude of the decreases demonstrated in Tables 4 and 5. To incorporate lagged effects into our analysis of social net benefits, we estimate FRD regressions with a rolling sum of 3-day healthcare expenditures as the dependent variable (Equation (8)).

Table 6 reports results from estimating Equation (8). The coefficient magnitudes are larger than the corresponding coefficients presented in Tables 4 and 5 , by factors ranging from 2.5 to 2.8 when focusing on all age groups and the first row of each sub-panel. The larger magnitudes can be partially explained by the nature of the South Korean AQAS, where many alerts last for at least one day beyond the initial date of issuance. Indeed, 80 of 134 unique alerts were issued for more than one day, and the average number of days per alert is approximately 1.87 . Nevertheless, this figure cannot fully explain the differences in the magnitudes mentioned above, which hints at potential lagged decreases in healthcare costs even after an alert expires.

To avoid double counting benefits when we conduct policy simulations, the estimation sample for the second row in each panel of Table 6 omits alert days on which the previous day was covered by an alert ${ }^{24}$ In general, the coefficients decrease in size; nevertheless, they are still approximately comparable in overall magnitude. Compared to the results in the first rows, the overall effects decrease by $8 \%$ to $19 \%$. Compared to estimates of contemporaneous effects, the coefficients are 2.2 or 2.5 times larger - figures above 1.87 , or the average number of days per alert.

\section{Robustness}

We first test the robustness of our results to including health expenditures from outpatient visits to tertiary hospitals. The medical referral process, which is required when visiting a tertiary hospital, generates a gap between the onset of symptoms and actual outpatient visits. We excluded those visits in our main analysis to clearly identify the immediate impacts of the AQAS, and we do not expect their inclusion to qualitatively change our main results since these expenditures comprise less than $15 \%$ of the total outpatient expenditures. Tables 7 and 8 confirm that our estimates are robust to the inclusion of tertiary outpatient visits. The coefficients and standard errors are of similar magnitudes to the analogous estimates in Tables 4 and 5 .

Table 9 estimates a variety of alternative specifications to demonstrate the robustness of our results. The most important modeling choice in most RD studies is the bandwidth

\footnotetext{
${ }^{24}$ Consider an alert that lasts for two consecutive days. If both days from the alert are within the analysis bandwidth (defined by PM levels), the 3-day impacts of both alert days would be counted separately even though there is a two-day overlap between the two 3-day sums of healthcare spending. By dropping alert days that immediately follow an alert day, we filter out any secondary sets of overlapping 3 -day sums for that particular alert.
} 
for the local linear regressions. The first three rows in each table present reduced-form estimates utilizing bandwidths of 16, 20 (our baseline specification), and $24{ }^{25}$ In the top panel of Table 9, the magnitude and significance of respiratory-illness effects for minors and all age groups remain stable across all bandwidths. In the bottom panel, cardiovascular-illness effects for both adult groups and all ages are statistically significant for the smaller bandwidth, in line with the main results, but they become insignificant for the larger bandwidth. We note, however, that the motivation for choosing a larger bandwidth is to trade off increased bias for a smaller standard error; in this context the standard error actually rises with the bandwidth, likely due to the increased meansquared error associated with higher pollution levels (see Figure 4), suggesting little gain from using a larger bandwidth. Appendix Table A6 reports analogous results for the dynamic effects specification; for both disease categories, the pooled age-group results remain statistically significant at all three bandwidths (16, 20, and 24).

Another concern in our context is the timing of advisories. In some instances, alerts may be triggered early in the morning but cancelled by $9 \mathrm{am}$; in others they may not be triggered until the evening. In either case, we would not expect the alerts to have meaningful effects on behavior. The last row in both panels of Table 9 filters out days with alerts cancelled before 9 am or triggered after $7 \mathrm{pm}$. As expected, the coefficients become slightly larger in magnitude and remain statistically significant.

In Appendix A3, we report a wide range of alternative specifications and robustness checks. Briefly, we find no evidence of manipulation of the running variable near the RD threshold (Appendix Figures A1 and A2) or a discontinuity in the control variables (Appendix Figure A3). Removing alert days on which the air quality warning was issued too late or too early yields similar results, as does accounting for the asymmetry in thresholds for alert issuance and cancellation (Appendix Table A7). We demonstrate that controlling for a quadratic of the running variable, a quadratic of the temperature variable, or the air quality variables (PM10, PM2.5, PM10 and PM2.5, and the Air Quality Index (AQI)) does not change our main conclusions (Appendix Tables A8 and A9). Our findings are also robust to using alternative sets of time fixed effects (Appendix Table A8) or clustering at different levels (Appendix Table A10). To test for spatial spillovers of alerts, we estimate the FRD regressions with the largest running variable observed in an adjacent alert region; Appendix Table A11 finds no effect of an adjacent region's alert on the focal region's health expenditures. Finally, we perform falsification tests by changing the RD threshold by 20,30, or 50 units from the true threshold; Appendix Table A11 demonstrates no statistically significant results at these placebo thresholds.

\section{Discussion}

We highlight several of our empirical findings. First, our results provide new insights on responses across broader disease categories. Previous studies on air pollution

\footnotetext{
${ }^{25}$ SLS estimates are identical to the reduced-form estimates after rescaling coefficients and standard errors by 1.6, as the first-stage estimates are insensitive to bandwidth choice.
} 
alerts have primarily analyzed respiratory symptoms - Neidell (2009) found effects on asthma-related hospitalizations, and Janke (2014) found effects on respiratory emergency admissions ${ }^{26}$ Our findings suggest that effects are not limited to respiratory diagnoses, as cardiovascular disease spending of adults also decreased significantly.

Second, our results yield novel findings of alerts' effects for adults. Neidell (2009) and Janke (2014) found statistically significant impacts of air quality warnings for the youngest ages ${ }^{27}$ In contrast, our results reveal that the benefits of air quality warnings may not be restricted to minors. While minors' health spending was reduced by 12.6 million USD, prime-age and older adults also demonstrated significant health expenditure decreases due to alerts, amounting to 20.4 million and 8 million USD, respectively. Our results imply that alerts can motivate all age groups to take appropriate avoidance measures, reducing the negative impacts of air pollution.

To calculate total benefits from decreased healthcare expenditures, we first tabulate the number of people exposed to the alerts in the seven major South Korean cities. As the FRD estimates measure the reduction in health spending per capita, we multiply the FRD estimates by the population affected by the alerts. Based on the coefficients of spending in the both disease categories across all ages, which sum to 9.1 cents per capita, the total reduction in health expenditures during 2016-2017 in seven major cities was approximately 41 million USD. This estimate considers only the alerts' contemporaneous effects. Incorporating dynamic effects into the calculation increases the reduction by about one third, for a total reduction in health expenditures of approximately 52 million USD 28

Combined with our theoretical framework, the empirical findings presented above can provide a lower bound on the gross benefits from the AQAS. Specifically, our framework implies that the reduction in public healthcare expenditures represents a lower bound on the gross benefits of the AQAS. Our health expenditure data contain the sum of private copayments and public coverage, with an approximate ratio of 7:3. Thus, approximately $70 \%$ of the FRD coefficients represents a reduction in public expenditures. Applying this share to the total expenditure reductions computed above yields lower bounds on gross benefits that amount to 18.4 million USD (respiratory) and 10.2 million USD (cardiovascular) respectively. Figure 5 presents lower bounds on gross benefits by age group, with non-elderly adults realizing the largest gross benefits. Benefits using estimates from the dynamic specification (Table 6) are somewhat larger than those using estimates from the contemporaneous specification (Tables 4 and 5) (24.5 million USD for respiratory and 12.2 million USD for cardiovascular), as the former captures a larger change in health expenditures than the latter.

\footnotetext{
${ }^{26}$ Chen et al. 2018, also find weak evidence of an effect on asthma-related visits.

${ }^{27}$ Mullins and Bharadwaj 2015) and Aguilar-Gomez (2020) both find effects of pollution warnings on elderly health outcomes. In their contexts, however, the warnings also reduce pollution levels, suggesting a direct effect of pollution on health. Our study estimates the pure effect of alerts on health expenditures, as measured PM does not change at the RD threshold. Furthermore, our welfare analysis framework would not apply to policies which reduce emissions, as these policies entail additional implicit net costs.

${ }^{28}$ For this calculation we must assume that the benefits of alerts do not decrease as the pollution level rises above the RD threshold, as our RD estimates are local to the RD threshold. This assumption seems plausible, however, as health damages must weakly increase with pollution, so the benefits of avoidance behavior likely increase as well.
} 
To quantify AQAS net benefits and benefit-cost ratios, we collected reports on environmental expenditures from the websites of the seven major cities' municipal governments. The cost of managing the alert system in 2017 was estimated at 2 million USD. To be conservative we include a wide range of expenditures in this estimate, from the price of sending alerts via text messages to the maintenance cost of the air pollution monitors ${ }^{29}$ As we could not obtain complete expenditure information for 2016, we assume that costs would be similar to 2017, yielding a total cost of 4 million USD in 2016-2017 ${ }^{30}$ The cost is considerably lower than the total health benefit calculated above, 28.6 million USD, yielding an approximate benefit:cost ratio of 7.1:1 and a net benefit of 24.6 million USD for 2016-2017. Incorporating the dynamic effects further increases the net benefits and the benefit:cost ratio to 32.7 million USD and 9.2:1, respectively. ${ }^{31}$

We also explore the potential welfare gains from expanding the alert system's covered range. For this analysis we consider two scenarios. In the first scenario, we assume that advisories are issued on all days on which the running variable exceeds zero (i.e. the fuzzy RD becomes a sharp RD). In the second scenario, we assume that the government tightens the advisory criterion for PM2.5 from $90 \mu \mathrm{g} / \mathrm{m}^{3}$ to $75 \mu \mathrm{g} / \mathrm{m}^{3}$ during our analysis period (2016-2017). This corresponds to an actual policy the government enacted starting July 2018. In both scenarios we assume that the magnitudes of the alerts' effects remain similar to our FRD estimates 3233

We find that expanding the alert system's coverage could yield significant benefits. Figure 6 presents net benefits for the baseline scenario and the two alternative scenarios. Issuing alerts whenever the RD threshold is exceeded would have reduced health expenditures by an additional 5.7 million USD (Scenario A) during our sample period, bringing the total reduction to 42.4 million USD (right panel). Lowering the threshold for alert issuance from $90 \mu \mathrm{g} / \mathrm{m}^{3}$ to $75 \mu \mathrm{g} / \mathrm{m}^{3}$ (for PM2.5) would have reduced total health expenditures by 76.5 million USD (Scenario B) during our sample period (right panel), or a 109\% increase from the baseline policy. Notably, this corresponds to the current alert criteria, implemented in July 2018. In all scenarios the benefits greatly exceed the costs, indicated by the solid or dashed horizontal lines for comparison.

\footnotetext{
${ }^{29}$ Appendix Tables A12 and A13 list the expenditure items and the sum of these expenditures by metropolitan city, respectively. See Appendix A2 for additional details.

${ }^{30}$ Government expenditures may vary year-to-year. We collected similar information for 2018 and found that total 2018 expenditures were approximately 2.8 million USD.

${ }^{31}$ Utilizing the 2018 expenditures as the reference cost leads to the total costs of 5.6 million USD. The corresponding net benefit is about 23 million USD, with a benefit:cost ratio of approximately 5.1:1. When considering dynamic effects, the total net benefit is 31.1 million USD, and the associated benefit:cost ratio is $6.6: 1$.

${ }^{32}$ Concerns may arise regarding "alert fatigue" in these simulations, as the number of days with alert issuance necessarily increases. It is worth noting, however, that the number of treated days remains modest even in those scenarios. The rates of alert district-days are $2.67 \%, 2.81 \%$, and $4.57 \%$ in the baseline scenario, Scenario A, and Scenario B, respectively. We thus assume that alert fatigue does not become a serious concern in these simulations.

${ }^{33} \mathrm{~A}$ related concern is that non-advisory days on which the running variable exceeds zero ("non-compliant" days) systematically differ from advisory days on which the running variable exceeds zero ("compliant" days). Indeed, as shown in Table 1 weather conditions influence alert issuance. We thus compared precipitation and temperature across non-compliant and compliant days falling within the running variable interval of $[0,40]$. Average precipitation and temperature on non-compliant days were $0.65 \mathrm{~mm}$ and $3.121 \mathrm{C}$, respectively, with standard deviations of $5.12 \mathrm{~mm}$ and $2.24 \mathrm{C}$. Average precipitation and temperature on compliant days were $1.215 \mathrm{~mm}$ and $7.618 \mathrm{C}$, respectively, with standard deviations of $6.12 \mathrm{~mm}$ and $3.79 \mathrm{C}$. We assume that these modest meteorological differences would not yield large differences in the alerts' impacts.
} 


\section{Conclusion}

Combining our RD estimates with a theoretical framework, we find lower bounds on the benefits of the South Korean air pollution alert system that greatly exceed the costs of operating the system. Given the insignificant changes in average PM levels at the RD threshold, we interpret our results as a "pure" effect of avoidance behavior, rather than a combined effect of avoidance behavior and reduced ambient pollution levels. Our results thus stand in contrast to those from some recent work, which found effects only in contexts in which alerts were combined with policies to reduce ambient pollution levels (Mullins and Bharadwaj, 2015; Aguilar-Gomez, 2020). Our theoretical framework is likely to prove applicable in other settings in which individuals endogenously respond to information provision but there are substantial externalities. For example, one might bound the welfare benefits of restaurant hygiene grade cards using the reduction in insurance-covered hospitalization costs (Jin and Leslie, 2003) or the benefits of electricity usage information using the reduction in environmental damages (Jessoe and Rapson, 2014).

Our study also highlights that manipulation of air pollution information for economic and political gains may be costly. If pollution alerts are not issued due to manipulation, the public may not engage in welfare-enhancing avoidance behaviors. Despite the alerts' benefits, governments may have incentives to distort air pollution information if they worry about temporary economic declines from decreased outdoor activities (Min, 2019). Furthermore, local government officials may have incentives to manipulate air pollution levels for more favorable evaluations (Andrews, 2008, Chen et al., 2012, Ghanem and Zhang, 2014; Zou, 2021). Our findings imply that these distortions can reduce public health and generate additional healthcare expenditures.

A primary limitation of our study is that the results apply specifically to South Korean metropolitan areas. While these areas are economically important in themselves, with a combined population of over 23 million, our estimates may not generalize to other countries. Nevertheless, there are good reasons to believe that our main qualitative finding - an AQAS can generate meaningful welfare gains - applies to other contexts. First, previous studies have found significant reductions in some types of healthcare utilization due to air-quality alerts. For example, Neidell (2009) found that alert-induced avoidance behavior decreased Los Angeles asthma hospitalizations between 12 and 60 percent, and Janke (2014) found that even alerts for "moderate" pollution levels reduced asthma admissions by 8 percent in England. Furthermore, South Korean healthcare prices are remarkably low by developed-country standards. For example, relative to South Korea, 2016 per capita health expenditures (PPP-adjusted) were 60 percent higher in the United Kingdom, 77 percent higher in France, 113 percent higher in Sweden, and 270 percent higher in the United States (Lorenzoni and Koechlin, 2017). Thus, even if avoidance behavior or high pollution levels are less prevalent in other countries than in South Korea, overall impacts on health expenditures may still be of similar magnitude. 


\section{REFERENCES}

Aguilar-Gomez, Sandra. 2020. "Adaptation and mitigation of pollution: evidence from air quality warnings." Working paper.

Anderson, Michael, and Jeremy Magruder. 2012. "Learning from the crowd: Regression discontinuity estimates of the effects of an online review database." The Economic Journal, 122(563): 957-989.

Anderson, Michael L. 2017. "The benefits of college athletic success: An application of the propensity score design." Review of Economics and Statistics, 99(1): 119-134.

Andrews, Steven Q. 2008. "Inconsistencies in air quality metrics: 'Blue Sky'days and PM10 concentrations in Beijing." Environmental Research Letters, 3(3): 034009.

Barwick, Panle Jia, Shanjun Li, Liguo Lin, and Eric Zou. 2020. "From fog to smog: The value of pollution information.” National Bureau of Economic Research.

Bollinger, Bryan, Phillip Leslie, and Alan Sorensen. 2011. "Calorie posting in chain restaurants." American Economic Journal: Economic Policy, 3(1): 91-128.

Calonico, Sebastian, Matias D Cattaneo, and Rocio Titiunik. 2014. "Robust nonparametric confidence intervals for regression-discontinuity designs." Econometrica, 82(6): 2295-2326.

Calonico, Sebastian, Matias D Cattaneo, and Rocio Titiunik. 2015. "rdrobust: An R Package for Robust Nonparametric Inference in Regression-Discontinuity Designs." The R Journal, 7(1): 38.

Cattaneo, Matias D, Luke Keele, Rocío Titiunik, and Gonzalo Vazquez-Bare. 2020. "Extrapolating treatment effects in multi-cutoff regression discontinuity designs." Journal of the American Statistical Association, 1-12.

Cellini, Stephanie Riegg, Fernando Ferreira, and Jesse Rothstein. 2010. "The value of school facility investments: Evidence from a dynamic regression discontinuity design." The Quarterly Journal of Economics, 125(1): 215-261.

Chen, Hong, Qiongsi Li, Jay S Kaufman, Jun Wang, Ray Copes, Yushan Su, and Tarik Benmarhnia. 2018. "Effect of air quality alerts on human health: a regression discontinuity analysis in Toronto, Canada." The Lancet Planetary Health, 2(1): e19e26.

Chen, Yuyu, Ginger Zhe Jin, Naresh Kumar, and Guang Shi. 2012. "Gaming in air pollution data? Lessons from China.” The BE Journal of Economic Analysis \& Policy, 13(3).

Chetty, Raj, Adam Looney, and Kory Kroft. 2009. "Salience and taxation: Theory and evidence." American Economic Review, 99(4): 1145-77. 
Finkelstein, Amy, and Nathaniel Hendren. 2020. "Welfare Analysis Meets Causal Inference." Journal of Economic Perspectives, 34(4): 146-67.

Gao, Xuwen, Ran Song, and Christopher Timmins. 2021. "The Role of Information in the Rosen-Roback Framework." National Bureau of Economic Research.

Gelman, Andrew, and Guido Imbens. 2019. "Why high-order polynomials should not be used in regression discontinuity designs." Journal of Business \& Economic Statistics, 37(3): 447-456.

Ghanem, Dalia, and Junjie Zhang. 2014. “'Effortless Perfection:'Do Chinese cities manipulate air pollution data?" Journal of Environmental Economics and Management, 68(2): 203-225.

Greenstone, Michael, Guojun He, Ruixue Jia, and Tong Liu. 2021. "Can Technology Solve the Principal-Agent Problem? Evidence from China's War on Air Pollution." American Economic Review: Insights.

Hastings, Justine S, and Jeffrey M Weinstein. 2008. "Information, school choice, and academic achievement: Evidence from two experiments." The Quarterly Journal of Economics, 123(4): 1373-1414.

Ito, Koichiro. 2014. "Do consumers respond to marginal or average price? Evidence from nonlinear electricity pricing." American Economic Review, 104(2): 537-63.

Ito, Koichiro, and Shuang Zhang. 2020. "Willingness to pay for clean air: Evidence from air purifier markets in China." Journal of Political Economy, 128(5): 1627-1672.

Janke, Katharina. 2014. "Air pollution, avoidance behaviour and children's respiratory health: Evidence from England." Journal of Health Economics, 38: 23-42.

Jessoe, Katrina, and David Rapson. 2014. "Knowledge is (less) power: Experimental evidence from residential energy use." American Economic Review, 104(4): 1417-38.

Jin, Ginger Zhe, and Phillip Leslie. 2003. "The effect of information on product quality: Evidence from restaurant hygiene grade cards." The Quarterly Journal of Economics, 118(2): 409-451.

Kang, Zi Yang, and Shoshana Vasserman. 2021. "Robust Bounds for Welfare Analysis.” Stanford University Working Paper.

Kling, Jeffrey R, Sendhil Mullainathan, Eldar Shafir, Lee C Vermeulen, and Marian V Wrobel. 2012. "Comparison friction: Experimental evidence from Medicare drug plans.” The Quarterly Journal of Economics, 127(1): 199-235.

Lechner, Michael. 2009. "Sequential causal models for the evaluation of labor market programs." Journal of Business \& Economic Statistics, 27(1): 71-83. 
Liu, Tong, Guojun He, and Alexis Lau. 2018. "Avoidance behavior against air pollution: evidence from online search indices for anti-PM 2.5 masks and air filters in Chinese cities." Environmental Economics and Policy Studies, 20(2): 325-363.

Lorenzoni, Luca, and Francette Koechlin. 2017. "International comparisons of health prices and volumes: new findings." Health Division.

Manski, Charles F, et al. 1997. "Monotone Treatment Response." Econometrica, 65(6): 1311-1334.

Mastromonaco, Ralph. 2015. "Do environmental right-to-know laws affect markets? Capitalization of information in the toxic release inventory." Journal of Environmental Economics and Management, 71: 54-70.

Min, Jiwon. 2019. "National survey on an awareness of air pollution." Korean Weekly Economic Review, 833(10): 1-12.

Mullins, Jamie, and Prashant Bharadwaj. 2015. "Effects of short-term measures to curb air pollution: Evidence from Santiago, Chile." American Journal of Agricultural Economics, 97(4): 1107-1134.

Neidell, Matthew. 2009. "Information, avoidance behavior, and health the effect of ozone on asthma hospitalizations." Journal of Human Resources, 44(2): 450-478.

Neidell, Matthew. 2010. "Air quality warnings and outdoor activities: evidence from Southern California using a regression discontinuity design.” Journal of Epidemiology \& Community Health, 64(10): 921-926.

Noonan, Douglas S. 2014. "Smoggy with a Chance of Altruism: The Effects of Ozone Alerts on Outdoor Recreation and Driving in Atlanta." Policy Studies Journal, 42(1): 122-145.

Organization for Economic Cooperation and Development. 2018. "OECD Economic Surveys Korea 2018." http://www.oecd.org/economy/surveys/Korea-2018OECD-economic-survey-overview.pdf, Accessed: 2020-10-29.

Saberian, Soodeh, Anthony Heyes, and Nicholas Rivers. 2017. "Alerts work! Air quality warnings and cycling." Resource and Energy Economics, 49: 165-185.

Ward, Alison L Sexton, and Timothy KM Beatty. 2016. "Who responds to air quality alerts?" Environmental and Resource Economics, 65(2): 487-511.

Zou, Eric Yongchen. 2021. "Unwatched pollution: The effect of intermittent monitoring on air quality." American Economic Review, 111(7): 2101-26. 
A

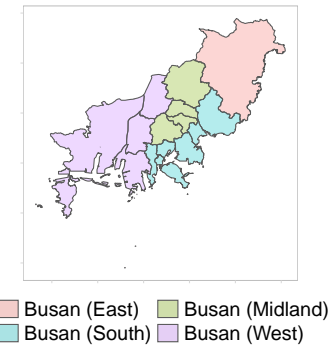

C

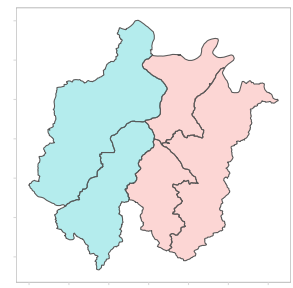

$\square$ Daejeon (East) $\square$ Daejeon (West)

E

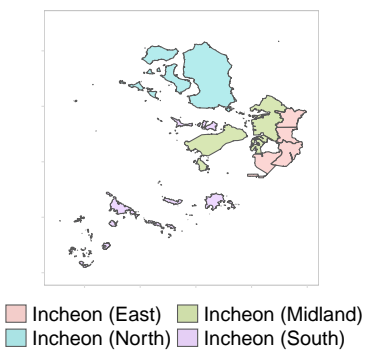

G

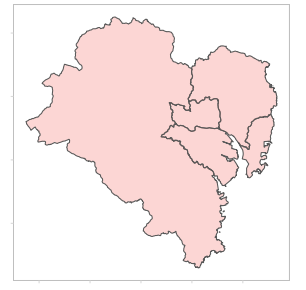

B

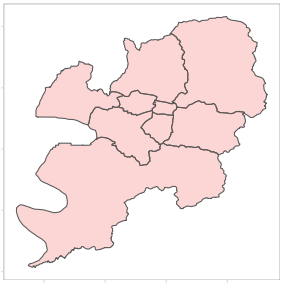

$\square$ Daegu

D

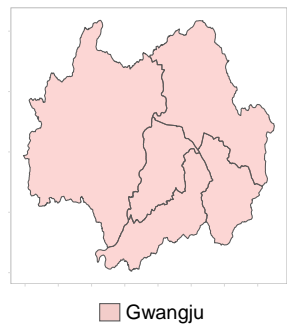

$\mathbf{F}$

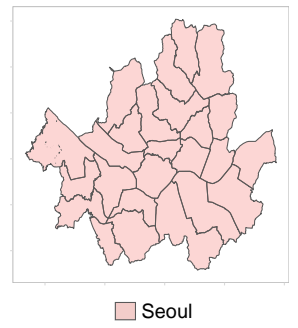

Figure 1. Alert Clusters for Seven Major Cities in South Korea

Notes: Panels A through G depict the alert clusters in Busan, Daejeon, Daegu, Gwangju, Incheon, Seoul, and Ulsan respectively. Different colors (in a given city) represent different alert clusters. Border lines separate districts in each major city area. 


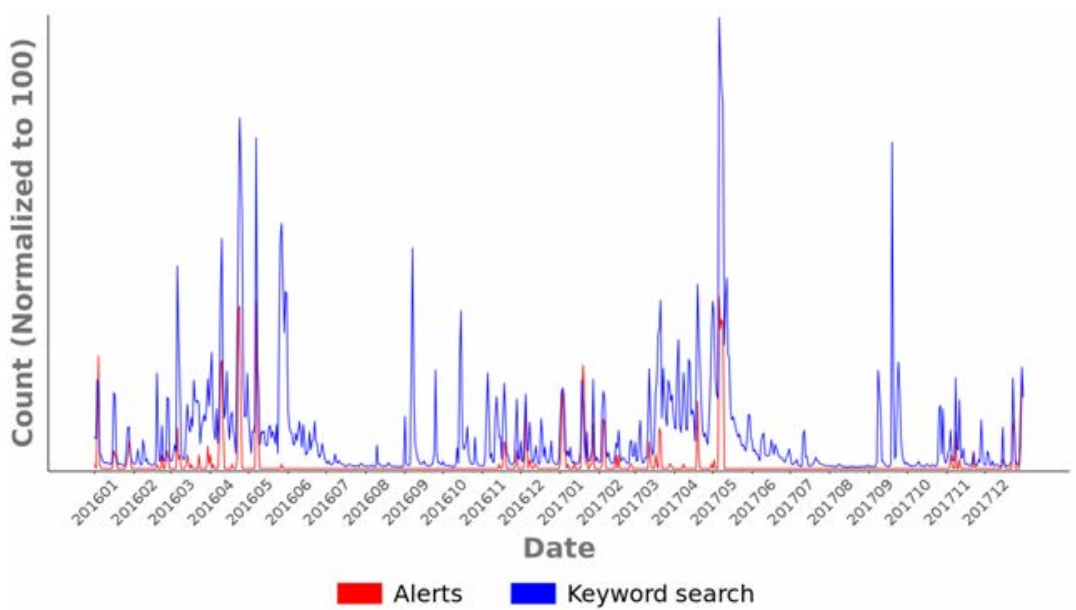

FIGURE 2. ALERT COUNTS AND KEYWORD SEARCH RESULTS RELATED TO AIR QUALITY INFORMATION

Notes: The red series represents the daily count of air quality alerts, and the blue series represents searches for "air pollution alert", "particulate matter", or "air quality" on NAVER. The maximum value of daily keyword search counts is set to 100 . 


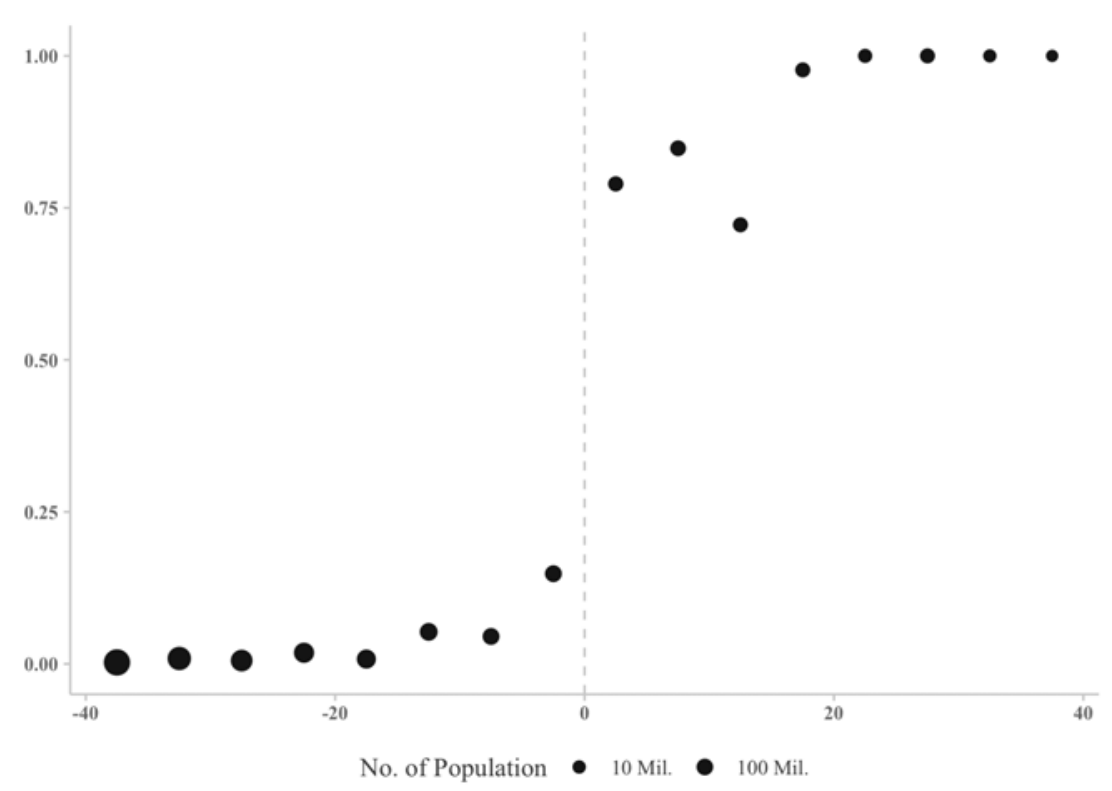

Notes: Each point represents the population-weighted average of observations in a given bin, the width of which is 5 units. The $y$-axis indicates the average probability of a particulate matter advisory. The $x$-axis indicates the value of the running variable (a threshold-normalized function of PM).

Figure 3. TReatment Discontinuity 

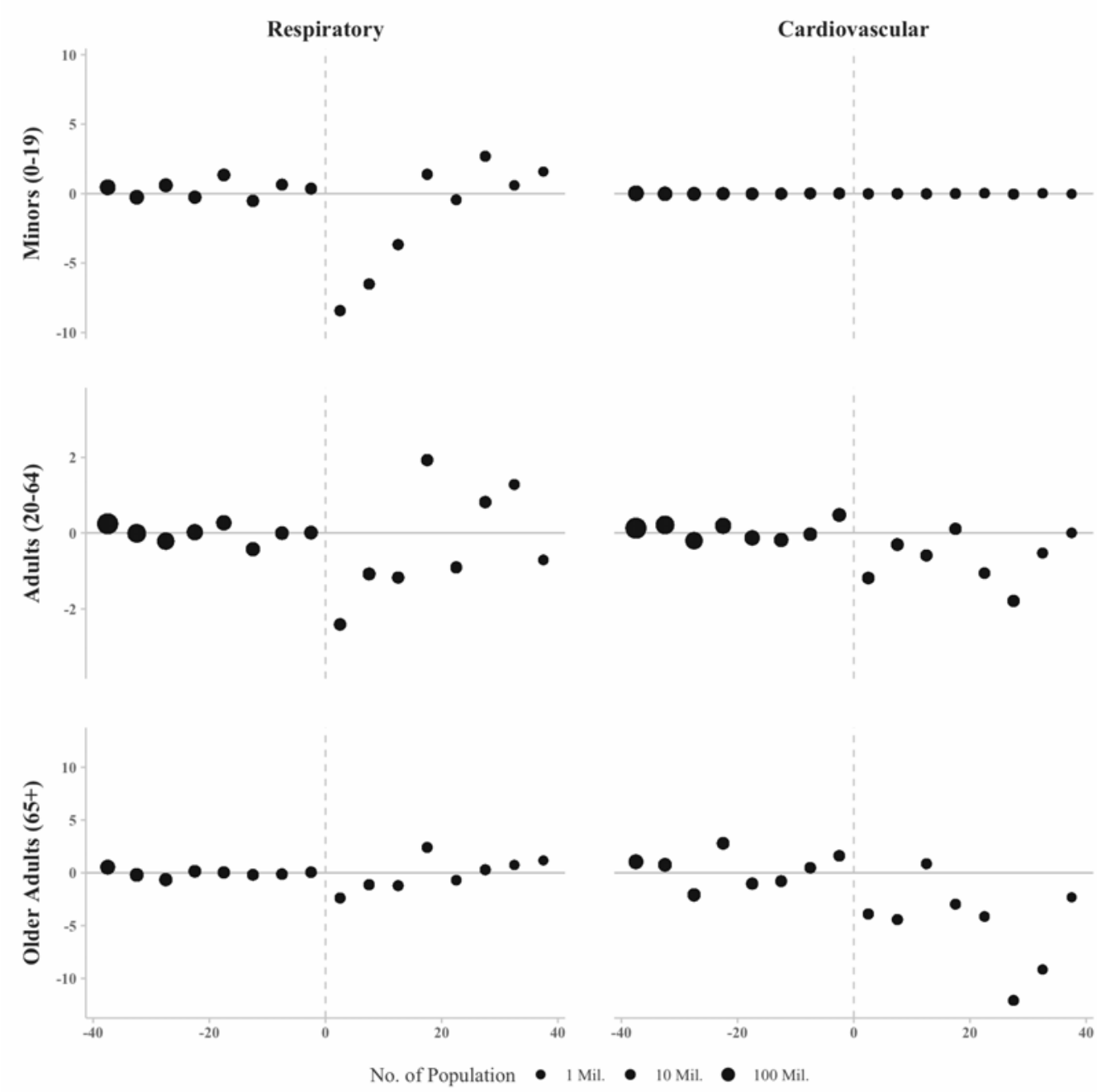

Notes: Each point represents the population-weighted average of observations in a given bin, the width of which is 5 units. The $y$-axis indicates the per capita level of residualized health expenditures, in US cents $(11.5 \mathrm{KRW}=0.01 \mathrm{USD})$. The residualization was performed with respect to day-of-week, yearby-month, holiday, and district fixed effects. The $x$-axis indicates the value of the running variable (a threshold-normalized function of PM).

FiguRE 4. OUtCome Discontinuity 


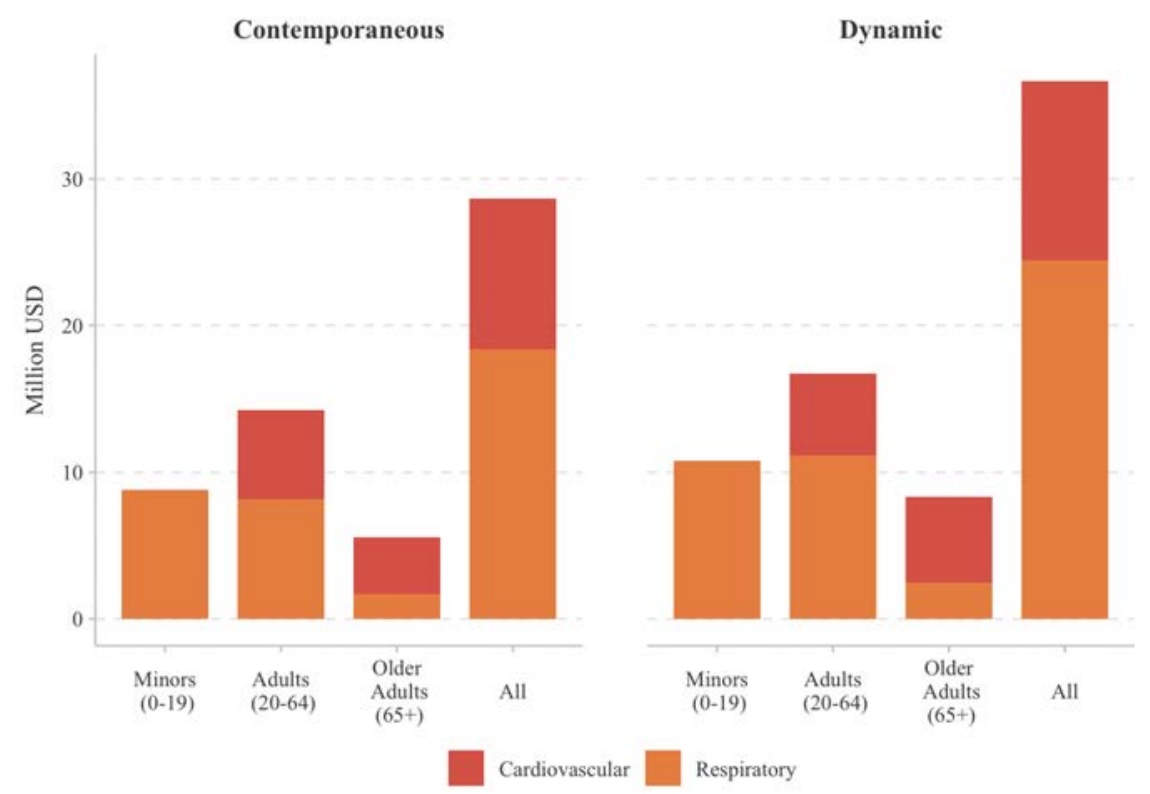

Figure 5. Potential Health Benefits by Age Group

Notes: The left (right) panel plots lower bounds on gross benefits by age groups using estimates from Tables 4 and 5 (Table 6). To bound gross benefits we scale the table coefficients by the average share of health expenditures that are publicly covered (70\%). 

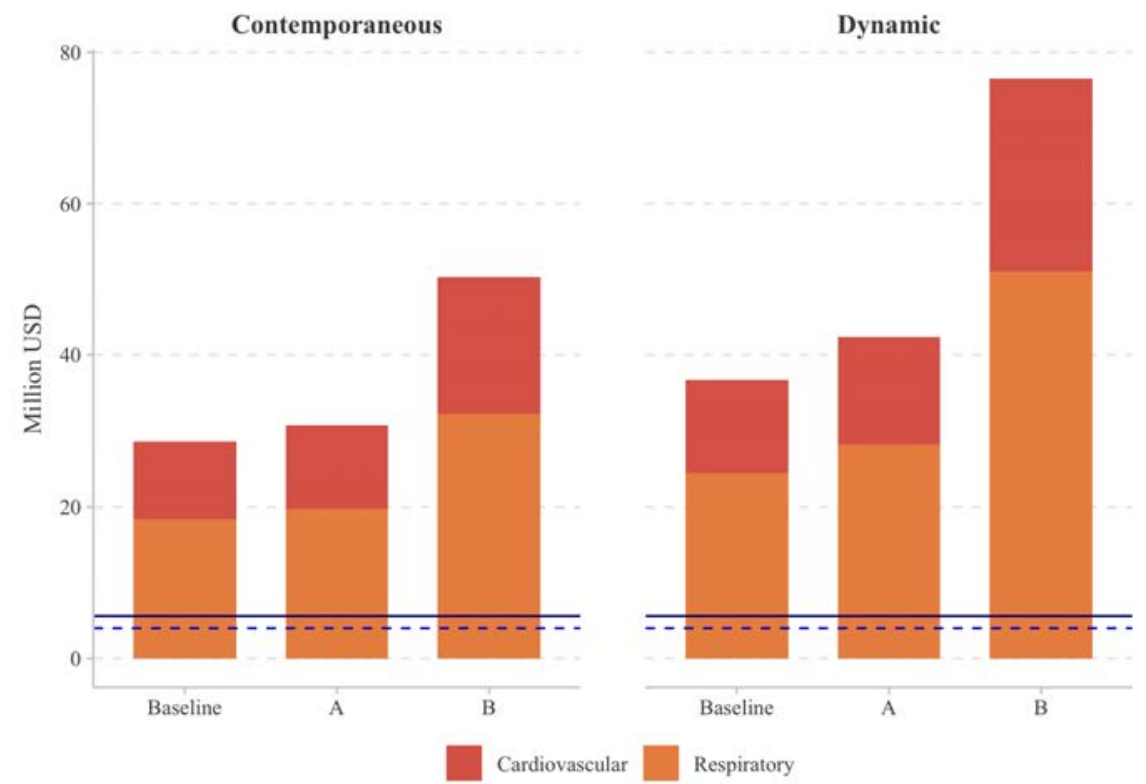

Figure 6. Cost-Benefit Comparison and Potential Health Benefits

Notes: The left (right) panel plots lower bounds on gross benefits by scenario using estimates from Tables 4 and 5 (Table 6). To bound gross benefits we scale the table coefficients by the average share of health expenditures that are publicly covered $(70 \%)$. "Baseline" represents the policy during the sample period, "Scenario A" represents a policy that triggers an alert whenever the running variable crosses the relevant threshold, and "Scenario B" represents a policy that lowers the PM2.5 threshold to the value adopted in July 2018. The solid (dashed) line represents the total system maintenance cost for the analytic period (2016-2017) using 2018 (2017) as the reference year for costs. 
TABle 1 - Thresholds And Guidelines of South Korean PM Advisories

\begin{tabular}{|c|c|c|}
\hline & \multicolumn{2}{|c|}{ PM Advisory Thresholds } \\
\hline & PM10 & PM2.5 \\
\hline Issuance & $\begin{array}{l}\text { Over } 150 \mu \mathrm{g} / \mathrm{m}^{3} \\
\text { for } 2 \text { hours }\end{array}$ & $\begin{array}{l}\text { Over } 90 \mu \mathrm{g} / \mathrm{m}^{3} \\
\text { for } 2 \text { hours }\end{array}$ \\
\hline Cancellation & $\begin{array}{l}\text { Under } 100 \mu \mathrm{g} / \mathrm{m}^{3} \\
\text { for } 1 \text { hour }\end{array}$ & $\begin{array}{l}\text { Under } 50 \mu \mathrm{g} / \mathrm{m}^{3} \\
\text { for } 1 \text { hour }\end{array}$ \\
\hline Target Groups & \multicolumn{2}{|c|}{ Guidelines } \\
\hline $\begin{array}{c}\text { General } \\
\text { Population }\end{array}$ & \multicolumn{2}{|c|}{$\begin{array}{l}\text { Stay indoors and reduce outdoor activities } \\
\text { Wear hygiene masks when you go outside } \\
\text { Reduce emissions (e.g. use public transportation) } \\
\text { Avoid roadways and construction sites }\end{array}$} \\
\hline $\begin{array}{c}\text { Children } \\
\& \text { Teenagers }\end{array}$ & \multicolumn{2}{|c|}{$\begin{array}{l}\text { Reduce or forbid outdoor classes. } \\
\text { Replace outdoor activities with indoor activities. } \\
\text { Enhance the hygiene management of dining facilities }\end{array}$} \\
\hline The Elderly & \multicolumn{2}{|c|}{ Enhance the hygiene management of dining facilities } \\
\hline
\end{tabular}


TABLE 2-SUMMARY STATISTICS - BANDWIDTH 40

\begin{tabular}{|c|c|c|c|c|c|c|c|c|}
\hline \multirow[b]{2}{*}{$\begin{array}{c}\text { Respiratory } \\
\text { Expenditures }\end{array}$} & \multicolumn{4}{|c|}{ Full Sample } & \multicolumn{4}{|c|}{ Bandwidth $=40$} \\
\hline & Mean & SD & Min & $\operatorname{Max}$ & Mean & $\mathrm{SD}$ & Min & Max \\
\hline$(0-19)$ & 46.0 & 23.2 & 0 & 201.8 & 50.1 & 24.9 & 0 & 171.6 \\
\hline$(20-64)$ & 21.3 & 14.0 & 0 & 239.8 & 23.3 & 14.8 & 0 & 147.2 \\
\hline Older Adults $(\geq 65)$ & 13.8 & 7.8 & 0 & 59.6 & 15.2 & 8.3 & 0 & 50.6 \\
\hline \multicolumn{9}{|l|}{$\begin{array}{c}\text { Cardiovascular } \\
\text { Expenditures }\end{array}$} \\
\hline Minors & 0.1 & 1.7 & 0 & 316.5 & 0.1 & 3.1 & 0 & 316.5 \\
\hline$(20-64)$ & 12.2 & 7.5 & 0 & 107.6 & 12.0 & 7.4 & 0 & 107.6 \\
\hline Older Adults $(\geq 65)$ & 65.1 & 42.7 & 0 & 268.9 & 64.3 & 42.1 & 0 & 248.5 \\
\hline \multicolumn{9}{|l|}{$\begin{array}{c}\text { Treatment } \\
\text { \& Covariates }\end{array}$} \\
\hline Alert & 0.03 & 0.2 & 0 & 1 & 0.1 & 0.3 & 0 & 1 \\
\hline$\left(\mu g / m^{3}\right)$ & 44.5 & 22.0 & 2.8 & 253.9 & 68.4 & 18.8 & 19.3 & 170.3 \\
\hline$\left(\mu g / m^{3}\right)$ & 25.1 & 12.9 & 1.6 & 109.5 & 41.8 & 13.4 & 6.6 & 109.5 \\
\hline Precipitation (mm) & 3.1 & 12.2 & 0 & 313.8 & 1.1 & 4.5 & 0 & 67 \\
\hline Temperature $\quad\left({ }^{\circ} \mathrm{C}\right)$ & 13.8 & 9.9 & -16.4 & 32.5 & 10.7 & 8.3 & -9.3 & 32 \\
\hline
\end{tabular}

Notes: The number of district-day observations are 53,363 and 10,547 for the full sample and the sample based on a bandwidth of 40, respectively. Morbidity spending variables are in US cents per capita (11.5 $\mathrm{KRW}=0.01 \mathrm{USD})$. 
TABLE 3-First-STAGe RegRession Results

\begin{tabular}{cccc}
\hline \hline & \multicolumn{3}{c}{ Bandwidth } \\
\cline { 2 - 4 } & 16 & 20 & 24 \\
\hline $\mathbb{1}(R V>=0)$ & 0.636 & 0.622 & 0.618 \\
& $(0.091)$ & $(0.091)$ & $(0.092)$ \\
& {$[0.122]$} & {$[0.114]$} & {$[0.110]$} \\
\hline Adjusted $\mathrm{R}^{2}$ & 0.708 & 0.720 & 0.728 \\
F-statistics & 46.029 & 65.351 & 89.686 \\
$\mathrm{~N}$ & 1,857 & 2,530 & 3,380 \\
\hline
\end{tabular}

Notes: This table reports three first-stage estimates of the change in advisory likelihood when the running variable crosses the RD threshold. These estimates are based on coefficients from three separate local-linear regressions, one for each reported bandwidth. The dependent variable in all regressions is an advisory indicator, and the independent variable of interest is an indicator for the running variable being above the RD threshold. All regressions control for the running variable, an interaction between the running variable and the indicator for the running variable being above the $\mathrm{RD}$ threshold, temperature, precipitation, and year-by-month and day-of-week fixed effects. The level of observation is the district by day, and observations are population weighted. Parentheses (square brackets) contain standard errors clustered by the running variable (day of sample). 
TABLE 4-RD RESULTS FOR RESPIRATORY DISEASES

\begin{tabular}{|c|c|c|c|c|}
\hline \multirow[b]{3}{*}{ Reduced form } & \multicolumn{4}{|c|}{ Age Group } \\
\hline & $\begin{array}{c}\text { Minors } \\
(0-19)\end{array}$ & $\begin{array}{l}\text { Adults } \\
(20-64)\end{array}$ & $\begin{array}{c}\text { Older } \\
\text { Adults } \\
(65+)\end{array}$ & All \\
\hline & & & & \\
\hline $\mathbb{1}(R V>=0)$ & $\begin{array}{l}-9.412 \\
(2.326) \\
{[2.930]}\end{array}$ & $\begin{array}{c}-2.346 \\
(1.391) \\
{[1.379]}\end{array}$ & $\begin{array}{c}-2.661 \\
(1.674) \\
{[1.860]}\end{array}$ & $\begin{array}{r}-3.624 \\
(1.437) \\
{[1.528]}\end{array}$ \\
\hline \multirow[b]{2}{*}{$\mathrm{RV} \cdot \mathbb{1}(R V>=0)$} & $\begin{array}{c}-0.074 \\
(0.143) \\
{[0.140]}\end{array}$ & $\begin{array}{c}-0.041 \\
(0.043) \\
{[0.045]}\end{array}$ & $\begin{array}{c}0.002 \\
(0.062) \\
{[0.069]}\end{array}$ & $\begin{array}{r}-0.038 \\
(0.056) \\
{[0.057]}\end{array}$ \\
\hline & $\begin{array}{c}0.645 \\
(0.167) \\
{[0.225]}\end{array}$ & $\begin{array}{c}0.214 \\
(0.113) \\
{[0.078]}\end{array}$ & $\begin{array}{c}0.167 \\
(0.129) \\
{[0.108]}\end{array}$ & $\begin{array}{c}0.270 \\
(0.110) \\
{[0.088]}\end{array}$ \\
\hline \multicolumn{5}{|l|}{ 2SLS } \\
\hline $\mathbb{1}(R V>=0)$ & $\begin{array}{c}-15.03 \\
(4.709) \\
{[5.674]}\end{array}$ & $\begin{array}{c}-3.777 \\
(2.195) \\
{[2.127]}\end{array}$ & $\begin{array}{r}-4.303 \\
(2.753) \\
{[2.804]}\end{array}$ & $\begin{array}{r}-5.829 \\
(2.397) \\
{[2.495]}\end{array}$ \\
\hline $\mathrm{RV}$ & $\begin{array}{c}0.039 \\
(0.204) \\
{[0.170]}\end{array}$ & $\begin{array}{c}-0.013 \\
(0.062) \\
{[0.055]}\end{array}$ & $\begin{array}{c}0.035 \\
(0.084) \\
{[0.083]}\end{array}$ & $\begin{array}{r}-0.006 \\
(0.084) \\
{[0.071]}\end{array}$ \\
\hline $\mathrm{RV} \cdot \mathbb{1}(R V>=0)$ & $\begin{array}{c}0.596 \\
(0.243) \\
{[0.305]}\end{array}$ & $\begin{array}{c}0.204 \\
(0.112) \\
{[0.078]}\end{array}$ & $\begin{array}{c}0.156 \\
(0.127) \\
{[0.106]}\end{array}$ & $\begin{array}{c}0.254 \\
(0.120) \\
{[0.105]}\end{array}$ \\
\hline $\begin{array}{c}\text { Adjusted } \mathrm{R}^{2} \\
\mathrm{~N}\end{array}$ & 0.836 & 0.866 & 0.797 & 0.893 \\
\hline
\end{tabular}

Notes: This table reports results from four reduced-form local-linear regressions (top panel) and four 2SLS local-linear regressions (bottom panel). The dependent variable in all regressions is respiratory disease expenditures for the relevant age group, measured in cents per capita $(11.5 \mathrm{KRW}=0.01 \mathrm{USD})$, and the independent variable of interest in the reduced-form (2SLS) regressions is an indicator for the running variable being above the RD threshold (advisory indicator). All regressions control for the running variable, an interaction between the running variable and the indicator for the running variable being above the RD threshold, temperature, precipitation, and year-by-month and day-of-week fixed effects. The level of observation is the district by day, and observations are population weighted. Parentheses (square brackets) contain standard errors clustered by the running variable (day of sample). The bandwidth is set to 20 in all regressions. 
TABle 5-RD Results For CARdiovascular Diseases

\begin{tabular}{|c|c|c|c|c|}
\hline \multirow[b]{3}{*}{ Reduced form } & \multicolumn{4}{|c|}{ Age Group } \\
\hline & $\begin{array}{c}\text { Minors } \\
(0-19)\end{array}$ & $\begin{array}{l}\text { Adults } \\
(20-64)\end{array}$ & $\begin{array}{c}\text { Older } \\
\text { Adults } \\
(65+)\end{array}$ & All \\
\hline & & & & \\
\hline $\mathbb{1}(R V>=0)$ & $\begin{array}{l}-0.025 \\
(0.021) \\
{[0.022]}\end{array}$ & $\begin{array}{l}-1.757 \\
(0.513) \\
{[0.481]}\end{array}$ & $\begin{array}{l}-5.962 \\
(2.070) \\
{[2.250]}\end{array}$ & $\begin{array}{l}-2.026 \\
(0.573) \\
{[0.622]}\end{array}$ \\
\hline \multirow[b]{2}{*}{$\mathrm{RV} \cdot \mathbb{1}(R V>=0)$} & $\begin{array}{c}0.003 \\
(0.001) \\
{[0.001]}\end{array}$ & $\begin{array}{c}0.056 \\
(0.023) \\
{[0.020]}\end{array}$ & $\begin{array}{c}0.234 \\
(0.102) \\
{[0.113]}\end{array}$ & $\begin{array}{c}0.066 \\
(0.024) \\
{[0.026]}\end{array}$ \\
\hline & $\begin{array}{l}-0.003 \\
(0.002) \\
{[0.002]}\end{array}$ & $\begin{array}{c}0.012 \\
(0.035) \\
{[0.037]}\end{array}$ & $\begin{array}{c}-0.083 \\
(0.158) \\
{[0.213]}\end{array}$ & $\begin{array}{c}0.006 \\
(0.038) \\
{[0.049]}\end{array}$ \\
\hline \multicolumn{5}{|l|}{ 2SLS } \\
\hline $\mathbb{1}(R V>=0)$ & $\begin{array}{l}-0.040 \\
(0.032) \\
{[0.035]}\end{array}$ & $\begin{array}{l}-2.828 \\
(0.976) \\
{[0.767]}\end{array}$ & $\begin{array}{l}-9.641 \\
(3.849) \\
{[3.677]}\end{array}$ & $\begin{array}{l}-3.259 \\
(1.086) \\
{[1.008]}\end{array}$ \\
\hline RV & $\begin{array}{c}0.003 \\
(0.001) \\
{[0.001]}\end{array}$ & $\begin{array}{c}0.077 \\
(0.029) \\
{[0.023]}\end{array}$ & $\begin{array}{c}0.308 \\
(0.104) \\
{[0.124]}\end{array}$ & $\begin{array}{c}0.090 \\
(0.030) \\
{[0.029]}\end{array}$ \\
\hline $\mathrm{RV} \cdot \mathbb{1}(R V>=0)$ & $\begin{array}{l}-0.003 \\
(0.002) \\
{[0.002]}\end{array}$ & $\begin{array}{c}0.005 \\
(0.042) \\
{[0.045]}\end{array}$ & $\begin{array}{l}-0.109 \\
(0.152) \\
{[0.228]}\end{array}$ & $\begin{array}{l}-0.003 \\
(0.039) \\
{[0.055]}\end{array}$ \\
\hline $\begin{array}{c}\text { Adjusted } \mathrm{R}^{2} \\
\mathrm{~N}\end{array}$ & 0.029 & 0.794 & 0.847 & 0.869 \\
\hline
\end{tabular}

Notes: This table reports results from four reduced-form local-linear regressions (top panel) and four 2SLS local-linear regressions (bottom panel). The dependent variable in all regressions is cardiovascular disease expenditures for the relevant age group, measured in cents per capita (11.5 KRW $=0.01 \mathrm{USD})$, and the independent variable of interest in the reduced-form (2SLS) regressions is an indicator for the running variable being above the RD threshold (advisory indicator). All regressions control for the running variable, an interaction between the running variable and the indicator for the running variable being above the RD threshold, temperature, precipitation, and year-by-month and day-of-week fixed effects. The level of observation is the district by day, and observations are population weighted. Parentheses (square brackets) contain standard errors clustered by the running variable (day of sample). The bandwidth is set to 20 in all regressions. 
TABLE 6-DYNAMIC IMPACTS

\begin{tabular}{|c|c|c|c|c|}
\hline \multirow[b]{2}{*}{ Respiratory Illness } & \multicolumn{4}{|c|}{ Age Group } \\
\hline & $\begin{array}{c}\text { Minors } \\
(0-19)\end{array}$ & $\begin{array}{l}\text { Adults } \\
(20-64)\end{array}$ & $\begin{array}{l}\text { Older } \\
\text { Adults } \\
(65+)\end{array}$ & All \\
\hline \multicolumn{5}{|l|}{ Dependent Variable } \\
\hline 3-day Spending & $\begin{array}{l}-38.220 \\
(11.551) \\
{[13.769]}\end{array}$ & $\begin{array}{c}-10.703 \\
(3.952) \\
{[4.661]}\end{array}$ & $\begin{array}{c}-12.977 \\
(4.951) \\
{[6.624]}\end{array}$ & $\begin{array}{c}-16.125 \\
(4.777) \\
{[5.935]}\end{array}$ \\
\hline $\begin{array}{l}\text { 3-day Spending } \\
\text { without Later } \\
\text { Alert Days }\end{array}$ & $\begin{array}{l}-38.616 \\
(12.422) \\
{[16.370]}\end{array}$ & $\begin{array}{l}-7.122 \\
(3.258) \\
{[3.262]}\end{array}$ & $\begin{array}{l}-8.202 \\
(4.427) \\
{[4.651]}\end{array}$ & $\begin{array}{c}-13.005 \\
(4.473) \\
{[5.381]}\end{array}$ \\
\hline \multicolumn{5}{|l|}{ Cardiovascular Illness } \\
\hline \multicolumn{5}{|l|}{ Dependent Variable } \\
\hline 3-day Spending & $\begin{array}{l}-0.064 \\
(0.086) \\
{[0.075]}\end{array}$ & $\begin{array}{l}-5.279 \\
(1.907) \\
{[1.993]}\end{array}$ & $\begin{array}{l}-30.388 \\
(12.229) \\
{[12.987]}\end{array}$ & $\begin{array}{l}-8.042 \\
(2.657) \\
{[3.057]}\end{array}$ \\
\hline $\begin{array}{l}\text { 3-day Spending } \\
\text { without Later } \\
\text { Alert Days }\end{array}$ & $\begin{array}{c}0.023 \\
(0.100) \\
{[0.094]}\end{array}$ & $\begin{array}{l}-4.486 \\
(1.706) \\
{[2.040]}\end{array}$ & $\begin{array}{l}-36.044 \\
(11.875) \\
{[13.975]}\end{array}$ & $\begin{array}{l}-7.414 \\
(2.515) \\
{[3.303]}\end{array}$ \\
\hline
\end{tabular}

Notes: This table reports results from 16 2SLS local-linear regressions. The dependent variable in all regressions is three-day respiratory or cardiovascular disease expenditures (from day $t$ to day $t+2$ ) for the relevant age group, measured in cents per capita $(11.5 \mathrm{KRW}=0.01 \mathrm{USD})$, and the independent variable of interest is an advisory indicator. All regressions control for the running variable, an interaction between the running variable and the indicator for the running variable being above the RD threshold, temperature, precipitation, and year-by-month and day-of-week fixed effects. The level of observation is the district by day, and observations are population weighted. Parentheses (square brackets) contain standard errors clustered by the running variable (day of sample). The bandwidth is set to 20 in all regressions. $\mathrm{N}=2,530$ in the first row of each panel. The last row of each panel drops from the sample advisory district-days on which the previous district-day experienced an advisory, which results in $\mathrm{N}=2,228$. 
TABLE 7-RD RESUlts For RESPIRATORy Diseases, With Visits to TERTIARy GENERAl Hospitals

\begin{tabular}{|c|c|c|c|c|}
\hline \multirow[b]{2}{*}{ Reduced form } & \multicolumn{4}{|c|}{ Age Groups } \\
\hline & $\begin{array}{c}\text { Minors } \\
(0-19)\end{array}$ & $\begin{array}{l}\text { Adults } \\
(20-64)\end{array}$ & $\begin{array}{c}\text { Older } \\
\text { Adults } \\
(65+)\end{array}$ & All \\
\hline $\mathbb{1}(R V>=0)$ & $\begin{array}{r}-8.804 \\
(2.344) \\
{[2.887]}\end{array}$ & $\begin{array}{l}-2.260 \\
(1.385) \\
{[1.381]}\end{array}$ & $\begin{array}{r}-2.532 \\
(1.655) \\
{[1.866]}\end{array}$ & $\begin{array}{r}-3.446 \\
(1.426) \\
{[1.505]}\end{array}$ \\
\hline RV & $\begin{array}{c}-0.086 \\
(0.145) \\
{[0.142]}\end{array}$ & $\begin{array}{c}-0.045 \\
(0.044) \\
{[0.045]}\end{array}$ & $\begin{array}{c}0.011 \\
(0.064) \\
{[0.072]}\end{array}$ & $\begin{array}{c}-0.044 \\
(0.057) \\
{[0.058]}\end{array}$ \\
\hline $\mathrm{RV} \cdot \mathbb{1}(R V>=0)$ & $\begin{array}{c}0.627 \\
(0.166) \\
{[0.227]}\end{array}$ & $\begin{array}{c}0.218 \\
(0.112) \\
{[0.079]}\end{array}$ & $\begin{array}{c}0.173 \\
(0.131) \\
{[0.114]}\end{array}$ & $\begin{array}{c}0.270 \\
(0.109) \\
{[0.088]}\end{array}$ \\
\hline \multicolumn{5}{|l|}{ 2SLS } \\
\hline $\mathbb{1}(R V>=0)$ & $\begin{array}{c}-14.062 \\
(4.662) \\
{[5.484]}\end{array}$ & $\begin{array}{l}-3.639 \\
(2.184) \\
{[2.134]}\end{array}$ & $\begin{array}{r}-4.095 \\
(2.696) \\
{[2.829]}\end{array}$ & $\begin{array}{r}-5.543 \\
(2.367) \\
{[2.450]}\end{array}$ \\
\hline RV & $\begin{array}{c}0.020 \\
(0.204) \\
{[0.170]}\end{array}$ & $\begin{array}{r}-0.018 \\
(0.063) \\
{[0.055]}\end{array}$ & $\begin{array}{c}0.021 \\
(0.084) \\
{[0.086]}\end{array}$ & $\begin{array}{c}-0.003 \\
(0.084) \\
{[0.071]}\end{array}$ \\
\hline $\mathrm{RV} \cdot \mathbb{1}(R V>=0)$ & $\begin{array}{c}0.581 \\
(0.237) \\
{[0.297]}\end{array}$ & $\begin{array}{c}0.208 \\
(0.110) \\
{[0.079]}\end{array}$ & $\begin{array}{c}0.162 \\
(0.127) \\
{[0.110]}\end{array}$ & $\begin{array}{c}0.254 \\
(0.118) \\
{[0.104]}\end{array}$ \\
\hline $\begin{array}{c}\text { Adjusted } \mathrm{R}^{2} \\
\mathrm{~N}\end{array}$ & \multicolumn{4}{|c|}{2,530} \\
\hline
\end{tabular}

Notes: This table reports results from four reduced-form local-linear regressions (top panel) and four 2SLS local-linear regressions (bottom panel). The dependent variable in all regressions is respiratory disease expenditures for the relevant age group, including visits to tertiary general hospitals and measured in cents per capita (11.5 KRW $=0.01 \mathrm{USD})$. The independent variable of interest in the reduced-form (2SLS) regressions is an indicator for the running variable being above the RD threshold (advisory indicator). All regressions control for the running variable, an interaction between the running variable and the indicator for the running variable being above the RD threshold, temperature, precipitation, and year-by-month and day-of-week fixed effects. The level of observation is the district by day, and observations are population weighted. Parentheses (square brackets) contain standard errors clustered by the running variable (day of sample). The bandwidth is set to 20 in all regressions. 
TABle 8-RD Results for Cardiovascular Diseases, With Visits to Tertiary General Hospitals

\begin{tabular}{|c|c|c|c|c|}
\hline \multirow[b]{2}{*}{ Reduced form } & \multicolumn{4}{|c|}{ Age Groups } \\
\hline & $\begin{array}{c}\text { Minors } \\
(0-19)\end{array}$ & $\begin{array}{l}\text { Adults } \\
(20-64)\end{array}$ & $\begin{array}{c}\text { Older } \\
\text { Adults } \\
(65+)\end{array}$ & All \\
\hline $\mathbb{1}(R V>=0)$ & $\begin{array}{l}-0.096 \\
(0.054) \\
{[0.062]}\end{array}$ & $\begin{array}{l}-1.877 \\
(0.527) \\
{[0.509]}\end{array}$ & $\begin{array}{l}-5.992 \\
(2.133) \\
{[2.421]}\end{array}$ & $\begin{array}{l}-2.133 \\
(0.618) \\
{[0.681]}\end{array}$ \\
\hline $\mathrm{RV}$ & $\begin{array}{c}0.005 \\
(0.003) \\
{[0.003]}\end{array}$ & $\begin{array}{c}0.059 \\
(0.025) \\
{[0.021]}\end{array}$ & $\begin{array}{c}0.216 \\
(0.100) \\
{[0.118]}\end{array}$ & $\begin{array}{c}0.065 \\
(0.025) \\
{[0.028]}\end{array}$ \\
\hline $\mathrm{RV} \cdot \mathbb{1}(R V>=0)$ & $\begin{array}{c}-0.003 \\
(0.007) \\
{[0.008]}\end{array}$ & $\begin{array}{c}0.012 \\
(0.038) \\
{[0.039]}\end{array}$ & $\begin{array}{c}-0.032 \\
(0.155) \\
{[0.214]}\end{array}$ & $\begin{array}{c}0.014 \\
(0.042) \\
{[0.052]}\end{array}$ \\
\hline \multicolumn{5}{|l|}{ 2SLS } \\
\hline $\mathbb{1}(R V>=0)$ & $\begin{array}{l}-0.153 \\
(0.095) \\
{[0.113]}\end{array}$ & $\begin{array}{l}-3.022 \\
(1.024) \\
{[0.789]}\end{array}$ & $\begin{array}{l}-9.691 \\
(3.930) \\
{[3.786]}\end{array}$ & $\begin{array}{l}-3.431 \\
(1.168) \\
{[1.073]}\end{array}$ \\
\hline RV & $\begin{array}{c}0.006 \\
(0.006) \\
{[0.004]}\end{array}$ & $\begin{array}{c}0.082 \\
(0.082) \\
{[0.025]}\end{array}$ & $\begin{array}{c}0.291 \\
(0.102) \\
{[0.129]}\end{array}$ & $\begin{array}{c}0.091 \\
(0.033) \\
{[0.033]}\end{array}$ \\
\hline $\mathrm{RV} \cdot \mathbb{1}(R V>=0)$ & $\begin{array}{c}0.003 \\
(0.007) \\
{[0.007]}\end{array}$ & $\begin{array}{c}0.003 \\
(0.044) \\
{[0.045]}\end{array}$ & $\begin{array}{l}-0.058 \\
(0.147) \\
{[0.227]}\end{array}$ & $\begin{array}{c}0.005 \\
(0.041) \\
{[0.057]}\end{array}$ \\
\hline $\begin{array}{c}\text { Adjusted } \mathrm{R}^{2} \\
\mathrm{~N}\end{array}$ & 0.022 & 0.799 & 0.854 & 0.874 \\
\hline
\end{tabular}

Notes: This table reports results from four reduced-form local-linear regressions (top panel) and four 2SLS local-linear regressions (bottom panel). The dependent variable in all regressions is cardiovascular disease expenditures for the relevant age group, including visits to tertiary general hospitals and measured in cents per capita (11.5 KRW $=0.01 \mathrm{USD})$. The independent variable of interest in the reduced-form (2SLS) regressions is an indicator for the running variable being above the RD threshold (advisory indicator). All regressions control for the running variable, an interaction between the running variable and the indicator for the running variable being above the RD threshold, temperature, precipitation, and year-by-month and day-of-week fixed effects. The level of observation is the district by day, and observations are population weighted. Parentheses (square brackets) contain standard errors clustered by the running variable (day of sample). The bandwidth is set to 20 in all regressions. 
TABLE 9-ROBUSTNESS CHECKS

\begin{tabular}{|c|c|c|c|c|}
\hline \multirow[b]{2}{*}{ Respiratory Illness } & \multicolumn{4}{|c|}{ Age Group } \\
\hline & $\begin{array}{l}\text { Minors } \\
(0-19)\end{array}$ & $\begin{array}{l}\text { Adults } \\
(20-64)\end{array}$ & $\begin{array}{c}\text { Older } \\
\text { Adults } \\
(65+)\end{array}$ & All \\
\hline Sample Modification & & & & \\
\hline Bandwidth: 16 & $\begin{array}{c}-12.504 \\
(4.256) \\
{[4.779]}\end{array}$ & $\begin{array}{l}-4.357 \\
(2.293) \\
{[2.071]}\end{array}$ & $\begin{array}{l}-4.468 \\
(2.626) \\
{[2.752]}\end{array}$ & $\begin{array}{l}-5.851 \\
(2.492) \\
{[2.391]}\end{array}$ \\
\hline Bandwidth: 20 & $\begin{array}{c}-15.033 \\
(4.709) \\
{[5.674]}\end{array}$ & $\begin{array}{l}-3.777 \\
(2.195) \\
{[2.127]}\end{array}$ & $\begin{array}{c}-4.303 \\
(2.753) \\
{[2.804]}\end{array}$ & $\begin{array}{c}-5.829 \\
(2.397) \\
{[2.495]}\end{array}$ \\
\hline Bandwidth: 24 & $\begin{array}{c}-14.049 \\
(4.521) \\
{[5.666]}\end{array}$ & $\begin{array}{l}-2.876 \\
(2.008) \\
{[2.009]}\end{array}$ & $\begin{array}{l}-2.393 \\
(2.918) \\
{[2.857]}\end{array}$ & $\begin{array}{l}-4.867 \\
(2.254) \\
{[2.387]}\end{array}$ \\
\hline $\begin{array}{c}\text { Without } \\
\text { Late/Early Advisories }\end{array}$ & $\begin{array}{c}-16.274 \\
(5.243) \\
{[6.248]}\end{array}$ & $\begin{array}{l}-4.093 \\
(2.316) \\
{[2.268]}\end{array}$ & $\begin{array}{l}-4.687 \\
(2.944) \\
{[2.996]}\end{array}$ & $\begin{array}{c}-6.320 \\
(2.550) \\
{[2.675]}\end{array}$ \\
\hline
\end{tabular}

\section{Cardiovascular Illness}

\begin{tabular}{ccccc}
\hline Sample Modification & & & & \\
\cline { 1 - 1 } Bandwidth: 16 & -0.042 & -2.781 & -7.426 & -2.994 \\
& $(0.039)$ & $(0.889)$ & $(2.897)$ & $(0.900)$ \\
& {$[0.035]$} & {$[0.675]$} & {$[3.327]$} & {$[0.864]$} \\
Bandwidth: 20 & -0.153 & -3.022 & -9.691 & -3.431 \\
& $(0.095)$ & $(1.024)$ & $(3.930)$ & $(1.168)$ \\
& {$[0.113]$} & {$[0.789]$} & {$[3.786]$} & {$[1.073]$} \\
Bandwidth: 24 & -0.019 & -1.654 & -4.469 & -1.870 \\
& $(0.030)$ & $(1.016)$ & $(4.320)$ & $(1.219)$ \\
Without & {$[0.035]$} & {$[0.838]$} & {$[3.850]$} & {$[1.087]$} \\
Late/Early Advisories & -0.043 & -3.064 & -10.502 & -3.533 \\
& $(0.034)$ & $(1.050)$ & $(4.217)$ & $(1.160)$ \\
& {$[0.038]$} & {$[0.834]$} & {$[4.012]$} & {$[1.091]$} \\
\hline
\end{tabular}

Notes: This table reports results from 32 2SLS local-linear regressions. The dependent variable in all regressions is respiratory or cardiovascular disease expenditures for the relevant age group, measured in cents per capita $(11.5 \mathrm{KRW}=0.01 \mathrm{USD})$, and the independent variable of interest is an advisory indicator. All regressions control for the running variable, an interaction between the running variable and the indicator for the running variable being above the RD threshold, temperature, precipitation, and year-by-month and day-of-week fixed effects. The level of observation is the district by day, and observations are population weighted. Parentheses (square brackets) contain standard errors clustered by the running variable (day of sample). The bandwidth is set to 20 unless otherwise noted. For bandwidths of 16, 20, and 24, N = 1,857, 2,530, and 3,380 respectively. The last row in each panel drops from the sample advisory district-days on which the advisory was cancelled before 9 am or triggered after $7 \mathrm{pm}$, which results in $\mathrm{N}=2,443$. 


\section{Online Appendix}

\section{A1. Generalization of Theoretical Framework}

For ease of exposition we present a model in which average daily PM is the running variable, but in our application the running variable is the maximum 2-hour minimum PM level (over one day). Here we show that our model's conclusions hold if the running variable is an arbitrary function of daily PM.

Suppose that individuals base their behavior on daily mean PM, $\overline{p m}$, while the running variable is a different function of daily $\mathrm{pm}, f(\mathrm{pm})$. The RD estimand then compares days on which $f(p m)$ is just above the alert threshold $(f(p m) \downarrow c)$ to those on which it is just below the alert threshold $(f(p m) \uparrow c)$.

Specify individual beliefs as

$$
\overline{p m}_{i}=\left\{\begin{array}{lll}
p m^{a v g} & \text { if } & f(p m)=f(p m) \uparrow c \\
p m^{h i} & \text { if } & f(p m)=f(p m) \downarrow c
\end{array}\right.
$$

where $\mathrm{pm}^{\mathrm{avg}}$ represents average daily mean PM conditional on $f(\mathrm{pm})$ being below the threshold $c$ and $p m^{h i}$ represents average daily mean PM conditional on $f(p m)$ being above the threshold $c$. Let $p m^{c}$ be average daily mean PM conditional on $f(p m)=c$. For our bounding exercise we assume that $p m^{h i} \approx p m^{c}$, or at least that $\left|p m^{h i}-p m^{c}\right|<<$ $\left|p m^{a v g}-p m^{c}\right|$. This representation is a reasonable approximation of our actual PM data. For example, in our PM2.5 data, $p m^{a v g}=22.7, p m^{h i}=66.7$, and $p m^{c}=57.5$. Thus $p m^{h i}$ is much closer to $\mathrm{pm}^{c}$ than $\mathrm{pm}^{\mathrm{avg}}$ is. More generally, the approximation only needs to be sufficiently accurate that the alerts do not cause individuals to behave less optimally than they would absent the alert's information.

Individuals maximize utility by choosing activity levels $a_{i}=\operatorname{argmax}_{a} U_{i}\left(a, \overline{p m}_{i}\right)$. Then

$$
U_{i}=\left\{\begin{array}{lll}
U_{i}\left(a_{i}\left(p^{a v g}\right), p m^{c}\right) & \text { if } & f(p m)=f(p m) \uparrow c \\
U_{i}\left(a_{i}\left(p m^{h i}\right), p m^{c}\right) & \text { if } & f(p m)=f(p m) \downarrow c
\end{array}\right.
$$

An individual's private change in utility from PM crossing the alert threshold is

$$
\begin{aligned}
& \Delta U_{i}=U_{i}\left(a_{i}\left(p m^{h i}\right), p m^{c}\right)-U_{i}\left(a_{i}\left(p m^{a v g}\right), p m^{c}\right)= \\
& \quad\left[b_{i}\left(a_{i}\left(p m^{h i}\right)\right)-b_{i}\left(a_{i}\left(p m^{a v g}\right)\right)\right]-s_{i}^{p v t}\left[p_{s}\left(a_{i}\left(p m^{h i}\right), p m^{c}\right)-p_{s}\left(a_{i}\left(p m^{a v g}\right), p m^{c}\right)\right] .
\end{aligned}
$$

Naturally $\Delta U_{i} \geq 0$ since $p m^{h i} \approx p m^{c}$ and $a_{i}=\operatorname{argmax}_{a} U_{i}\left(a, p m_{i}\right)$ - i.e. more accurate PM information can only (weakly) increase the individual's utility — but accurately quantifying $\Delta U_{i}$ is challenging even with good data on $s_{i}^{p v t}$. This challenge arises because it is difficult to estimate $b_{i}\left(a_{i}\right)$, the benefits of different activities (and thus the costs of avoidance behaviors); $a_{i}$ may be high dimensional, and researchers rarely have data on all, or even most, elements of $a_{i}$. 


\section{A2. Additional Data Notes}

Procedure for Calculating Running Variable: To be consistent with the particulate pollution alert system, we first calculate the 2-hour-minimum of particulate matter $\left(P M_{d h}^{2 h} \mathrm{~min}\right)$ in hour $h$ on day $d$. Next, we obtain a daily maximum of 2-hour-minimum PM measures in each hour and subtract the alert thresholds $(c)$, where $c=150$ in case of PM10 and $c=90$ (or 75 since March 27th of 2018) in case of PM2.5. These transformations generate the daily running variables $\left(r v_{d}\right)$. Last, we utilize the running variables rounded to the nearest integer. The process may be summarized as follows:

$$
\begin{gathered}
\text { 1. } P M_{d h}^{2 h \min }=\min _{h}\left\{P M_{d(h-1)}, P M_{d h}\right\} \quad(d: \text { date, h: hour }) \\
\text { 2. } P M_{d}^{2 h \min \max }=\max _{d}\left\{P M_{d h}^{2 h}{ }^{\min }\right\} \\
\text { 3. } r v_{d}=P M_{d}^{2 h} \min \max -c
\end{gathered}
$$

4. Rounding $r v_{d}$ to the nearest integer

As expected, our running variable has a tight correlation with PM10 and PM2.5, respectively. It is thus reasonable to believe the running variable captures the relationship between particulate pollution and health expenditures in the main regression. Nevertheless, we also control for different combinations of air quality variables as a robustness check (Appendix Table A9).

Cost Evaluation of Air Pollution Alert System: To determine alert system costs, we first searched for reports about environmental expenditures from the seven major cities in our study. We identified a category entitled "Air Pollution Management System Public Management Cost." Among the items listed under this category, we selected the ones related to the air pollution alert system (Appendix Table A12). We considered not only directly related items, such as the cost for issuing alerts via SMS, but also broadly related items, such as the management cost of air pollution monitors. Appendix Table A13 presents the total costs of the alert system for each city.

\section{A3. Additional Robustness Checks}

Manipulation Test: In other contexts researchers have found evidence that pollution measurements are manipulated to remain below certain thresholds. While the officials charged with determining alerts in our context face no obvious incentives to manipulate PM measurements, we nevertheless check to see whether there is any "missing" density of the running variable above the RD threshold. Appendix Figures A1 and A2 plot the distribution of the daily and hourly running variables, respectively. In both graphs, we see no unusual decrease in the density of observations above the threshold.

Control Continuity: Our main control variables are weather variables. We test the continuity of the two weather variables in our model, temperature and precipitation, at the 
RD threshold. Appendix Figure A3 shows the average temperature and precipitation per district and day-of-the-sample plotted against the running variable, which lies in the interval $[-40,40]$. There is no visual evidence of a discontinuity in either weather variable at the RD threshold.

Asymmetry in the Thresholds for Alert Issuance and Cancellation: Following the issuance of an alert, the running variable generally needs to drop substantially below the RD threshold before the alert gets canceled. To test the sensitivity of our results to this asymmetry in issuance and cancellation of alerts, we consider two sample restrictions. First, we trim the sample to exclude alert days following the first day of an air quality alert and report parameter estimates obtained from the main specification. Alternatively, we drop out alert days on which the running variable is below zero. The results of these exercises, reported in Appendix Table A7, suggest that our estimates are not sensitive to the asymmetry in the issuance and cancellation thresholds.

No Treatment During Nighttime Hours: It seems unlikely that most individuals modify their behavior in response to an air quality alert issued during nighttime hours. As a robustness check, we estimate FRD regressions when dropping district-days on which alerts were issued between $6 \mathrm{AM}$ and $9 \mathrm{PM}$ or between 8 AM and $8 \mathrm{PM}$. The results, reported in Appendix Table A7, are of similar magnitude to the estimates from our base model.

Alternative RD Specifications: Appendix Table A8 reports estimates from alternative $\mathrm{RD}$ specifications that control for a quadratic of the running variable. The health expenditure effects are of similar magnitude and statistical significance as our main results. We also check robustness to specifications in which we control for a quadratic in temperature or in which we control for year and month fixed effects instead of year-by-month fixed effects. Both sets of results are qualitatively similar to our main estimates.

Addition of Different Air Quality Variables We interpret our results as representing benefits of avoidance behavior. If the alerts had a direct effect on pollution levels, however, then our results would represent a combination of the benefits of avoidance behavior and lower ambient pollution levels. Appendix Table A4 demonstrates that there is no discontinuous change in ambient PM levels at the RD threshold. As an extra check we estimate specifications, reported in Appendix Table A9 that control for PM10, PM2.5, both PM measures, or the AQI. The addition of these air-quality controls has virtually no impact on our RD estimates.

Different Standard Error Clusters: The panel nature of our data is atypical for a RD design. We thus consider the impacts of different clustering choices for the standard errors. Appendix Table A10 reports the standard errors clustered at different combinations of spatial and time units. All coefficients that were significant in Tables 4 and 5 remain significant across all clustering choices. 
Spillover Effects: Our RD estimates could be attenuated if alerts affect health spending in adjacent regions. To address this concern, we estimate the impact of PM alerts in the nearest alert region to region $r$ on the outcome variables in region $r$. Appendix Table A11 demonstrates that the RD estimates are not statistically significant across all three age groups, suggesting an absence of spillover effects of the alerts to other regions.

Falsification Test: As the final robustness check, we estimate effects at alternative "placebo" RD thresholds. Specifically, we construct alternative running variables by subtracting 20,30, or 50 units from PM10 and PM2.5 concentration. All of the estimates for alternative running variables are statistically insignificant (Appendix Table A11), as would be expected if our research design is valid. 


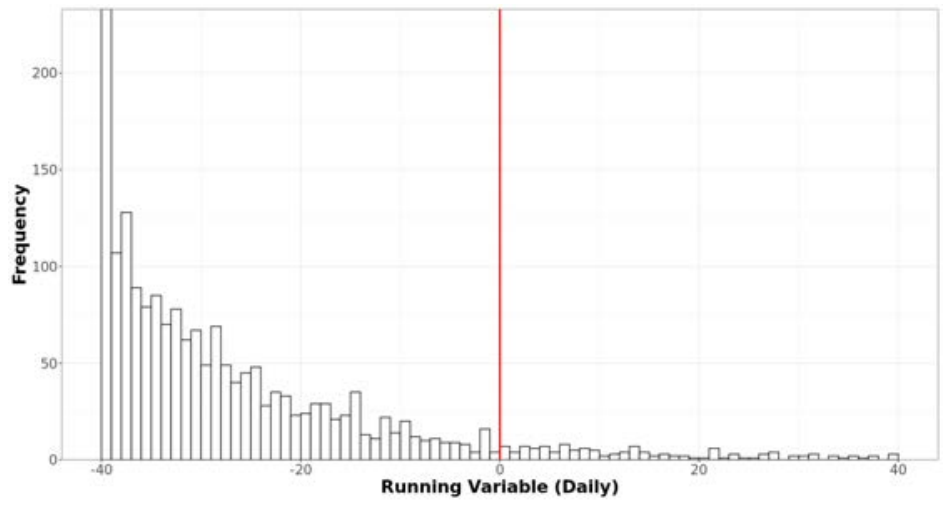

Figure A1. Histogram of RUNNING VARIABLE (DAILY)

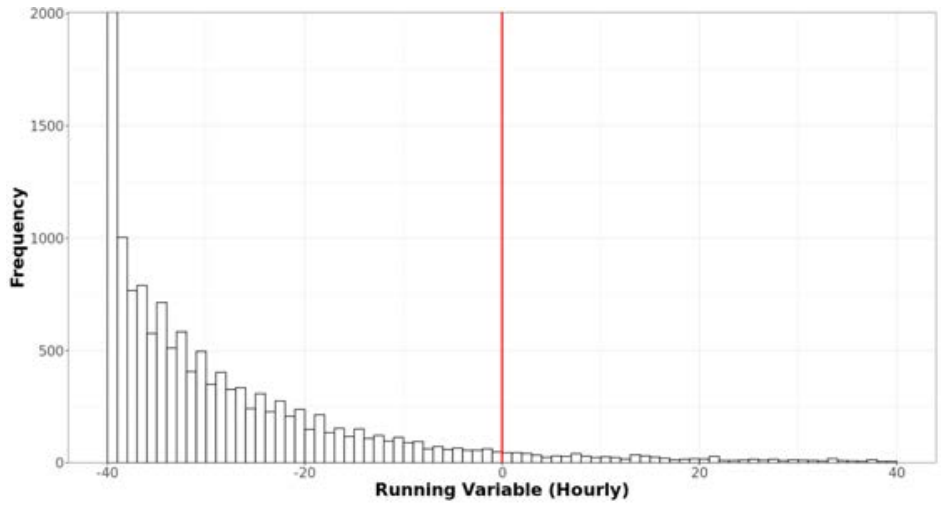

Figure A2. Histogram of RUNNING VARIABLE (HourLY)

Notes: The red line denotes the RD threshold of zero. 


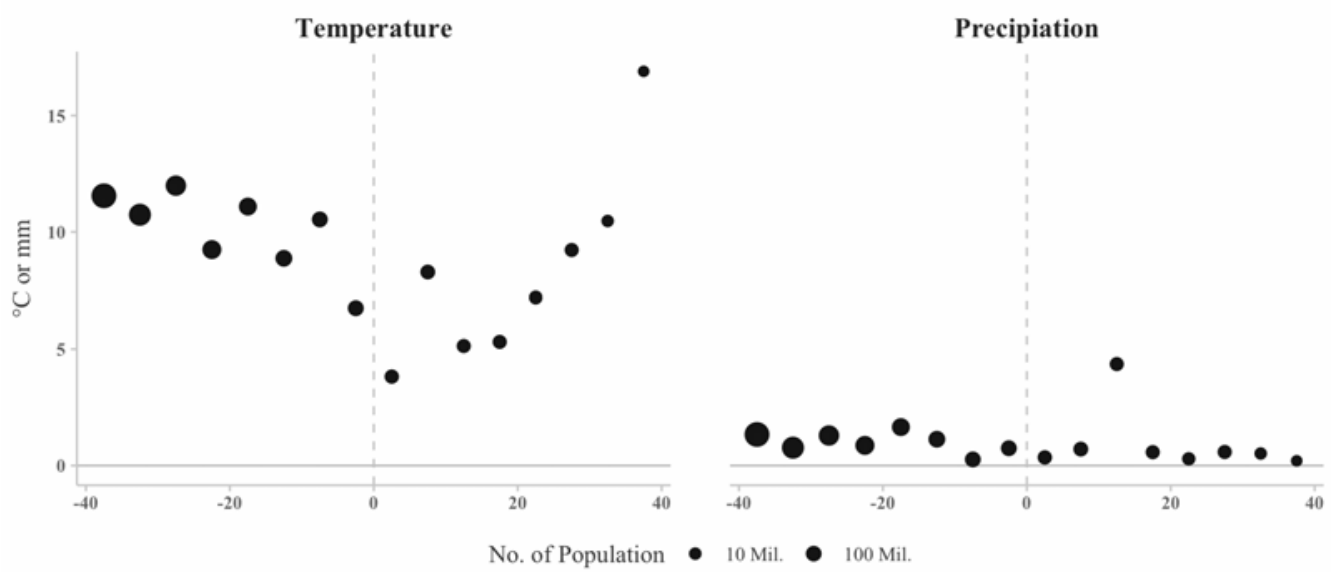

Notes: Each point represents the population-weighted average of observations in a given bin, the width of which is 5 units. The $y$-axis indicates the average temperature or rainfall. The $x$-axis indicates the value of the running variable (a threshold-normalized function of PM).

FIgURE A3. CONTINUITY OF CONTINUOUS CONTROL VARIABLES 
TABle A1-EXAmples of Alert Systems IN THE WORLD

\begin{tabular}{|c|c|c|c|c|}
\hline Alert Policies & Country & $\begin{array}{l}\text { Regions } \\
\text { Covered }\end{array}$ & $\begin{array}{c}\text { Estimated } \\
\text { Population } \\
\text { Covered } \\
\text { (mil.) }\end{array}$ & $\begin{array}{l}\text { Related } \\
\text { Links }\end{array}$ \\
\hline 4-tier Alert system & China & All & $1,387.2$ & LINK \\
\hline $\begin{array}{c}\text { Particulate Matter } \\
\text { Alerts }\end{array}$ & $\begin{array}{l}\text { South } \\
\text { Korea }\end{array}$ & All & 51.7 & LINK \\
\hline EnviroFlash & US & Many & 193.8 & LINK \\
\hline $\begin{array}{l}\text { Public Weather } \\
\text { Alerts }\end{array}$ & Canada & Ontario & 14.6 & LINK \\
\hline Air quality alerts & Australia & $\begin{array}{l}\text { New South } \\
\text { Wales }\end{array}$ & 8.2 & LINK \\
\hline $\begin{array}{c}\text { Sistema de } \\
\text { Monitoreo } \\
\text { Atmosférico }\end{array}$ & Mexico & $\begin{array}{l}\text { Mexico } \\
\text { City }\end{array}$ & 8.8 & LINK \\
\hline Haze Alerts & Singapore & All & 5.6 & LINK \\
\hline Pollution Alerts & UK & All & 66.7 & LINK \\
\hline
\end{tabular}


Table A2-Types of Medical Institutions in South Korea

\begin{tabular}{|c|c|c|}
\hline $\begin{array}{l}\text { Levels of } \\
\text { Institutions }\end{array}$ & $\begin{array}{c}\text { Types of } \\
\text { Institutions }\end{array}$ & Description \\
\hline Tertiary & $\begin{array}{l}\text { Tertiary } \\
\text { General } \\
\text { Hospitals }\end{array}$ & $\begin{array}{l}\text { The Minister of Health and Welfare may designate } \\
\text { a general hospital providing highly specialized } \\
\text { medical services for treating serious diseases } \\
\text { as a tertiary hospital among general hospitals. }\end{array}$ \\
\hline \multirow{2}{*}{ Secondary } & $\begin{array}{c}\text { General } \\
\text { Hospitals }\end{array}$ & - A general hospital shall have at least 100 beds. \\
\hline & Hospitals & $\begin{array}{l}\text { Hospitals shall have at least } 30 \text { beds or beds for } \\
\text { long-term care. }\end{array}$ \\
\hline \multirow[t]{2}{*}{ Primary } & $\begin{array}{l}\text { Public } \\
\text { Health } \\
\text { Centers }\end{array}$ & . Publicly owned regional healthcare institutions \\
\hline & Clinic & $\begin{array}{l}\text { A medical institution in which a doctor, dentist, } \\
\text { or oriental medical doctor provides } \\
\text { medical services primarily to outpatients }\end{array}$ \\
\hline
\end{tabular}

Sources: Korea Law Translation Center, Korea Legislation Research Institute

https://elaw.klri.re.kr/kor_service/lawView.do?hseq=53532\&lang=ENG, accessed on Sep 15, 2021

Notes: Source link provides additional details on the definitions of each institution type. 
TABle A3-OUt-OF-POCKET Payments For OutPatient Visits in the South Korean HeAlthCARE System

\begin{tabular}{|c|c|c|}
\hline $\begin{array}{c}\text { Type of } \\
\text { Institutions }\end{array}$ & Cases & Out-of-pocket Payments \\
\hline $\begin{array}{c}\text { Tertiary } \\
\text { Hospitals }\end{array}$ & $\begin{array}{l}\text { Normal } \\
\text { Patients }\end{array}$ & $\begin{array}{l}100 \% \text { of consultation fee }+ \\
40 \% \text { of remaining medical expenses } \\
\cdot(\text { Pregnant Women }) 40 \% \text { of total medical expenses } \\
\cdot(\text { Age }<1) 20 \% \text { of total medical expenses }\end{array}$ \\
\hline \multirow{2}{*}{$\begin{array}{c}\text { General } \\
\text { Hospitals }\end{array}$} & $\begin{array}{l}\text { Urban } \\
\text { Areas }\end{array}$ & $\begin{array}{l}\cdot 50 \% \text { of total medical expenses } \\
\cdot(\text { Pregnant Women }) 40 \% \text { of total medical expenses } \\
\cdot(\text { Age }<1) 20 \% \text { of total medical expenses }\end{array}$ \\
\hline & $\begin{array}{l}\text { Rural } \\
\text { Areas }\end{array}$ & $\begin{array}{l}\cdot 45 \% \text { of total medical expenses } \\
\cdot(\text { Pregnant Women }) 40 \% \text { of total medical expenses } \\
\cdot(\text { Age }<1) 20 \% \text { of total medical expenses }\end{array}$ \\
\hline \multirow{2}{*}{ Hospitals } & $\begin{array}{l}\text { Urban } \\
\text { Areas }\end{array}$ & $\begin{array}{l}\cdot 40 \% \text { of total medical expenses } \\
\cdot(\text { Pregnant Women }) 20 \% \text { of total medical expenses } \\
\cdot(\text { Age }<1) 10 \% \text { of total medical expenses }\end{array}$ \\
\hline & $\begin{array}{l}\text { Rural } \\
\text { Areas }\end{array}$ & $\begin{array}{l}\cdot 35 \% \text { of total medical expenses } \\
\cdot(\text { Pregnant Women }) 40 \% \text { of total medical expenses } \\
\cdot(\text { Age }<1) 20 \% \text { of total medical expenses }\end{array}$ \\
\hline \multirow[t]{2}{*}{ Clinics } & Age $\geq 65$ & $\begin{array}{l}\cdot W 1,500 \text { when total medical expenses } \leq W 15,000 \\
\cdot 10 \% \text { when total medical expenses } \\
>\$ 15,000 \& \leq W 20,000 \\
\cdot 20 \% \text { when total medical expenses } \\
>W 20,000 \& \leq W 25,000 \\
\cdot 30 \% \text { when total medical expenses }>W 25,000\end{array}$ \\
\hline & Age $<65$ & $\begin{array}{l}\cdot 30 \% \text { of total medical expenses } \\
\cdot(\text { Pregnant Women }) 10 \% \text { of total medical expenses } \\
\cdot(\text { Age }<1) 5 \% \text { of total medical expenses }\end{array}$ \\
\hline \multirow{2}{*}{$\begin{array}{l}\text { Public } \\
\text { Health } \\
\text { Centers }\end{array}$} & Age $\geq 6$ & $\begin{array}{l}30 \% \text { when total medical expenses }>\$ 12,000 \\
\text { W500- } \$ 2,200 \text { depending on cases } \\
\text { when total medical expenses } \leq \$ 12,000\end{array}$ \\
\hline & Age $<6$ & $\begin{array}{l}\cdot 21 \% \text { when total medical expenses }>W 12,000 \\
\text {. W500- } W 2,200 \text { depending on cases } \\
\text { when total medical expenses } \leq W 12,000\end{array}$ \\
\hline
\end{tabular}

Sources: Health Insurance Review and Assessment Service (HIRA) of South Korea https://www.hira.or.kr/dummy.do?pgmid=HIRAA030056020110 (in Korean), accessed on Sep 10, 2021

Notes: indicates Korean Won (KRW). 10,000 KRW is equivalent to approximately 8.7 USD. While this table shows general out-of-pocket payment ratios, it does not describe every specific case that could result in different ratios of out-of-pocket payments. For more details, refer to source link above. 
Table A4-FRD Results using Particulate Matter as Dependent Variables

\begin{tabular}{cccc}
\hline \hline \multirow{2}{*}{ Dependent Variable } & \multicolumn{3}{c}{ Bandwidths } \\
\cline { 2 - 4 } & 16 & 20 & 24 \\
\hline \multirow{2}{*}{ PM10 } & 0.331 & 1.685 & 4.190 \\
& $(4.989)$ & $(4.112)$ & $(3.362)$ \\
PM2.5 & -3.613 & -4.738 & -4.098 \\
& $(4.363)$ & $(4.692)$ & $(4.590)$ \\
\hline
\end{tabular}

Notes: This table reports results from six 2SLS local-linear regressions. The dependent variable in all regressions is PM10 or PM2.5, measured in cents $\mu \mathrm{g} / \mathrm{m}^{3}$, and the independent variable of interest is an advisory indicator. All regressions control for the running variable, an interaction between the running variable and the indicator for the running variable being above the RD threshold, temperature, precipitation, and year-by-month and day-of-week fixed effects. The level of observation is the district by day, and observations are population weighted. Parentheses contain standard errors clustered by the day of sample. The bandwidth varies across columns as noted. 
TABLE A5-OPTIMAL BANDWIDTH

\begin{tabular}{lc}
\hline \hline \multicolumn{1}{c}{ Dependent Variable } & Optimal Bandwidth \\
\hline Resp. (All) & 18.321 \\
Resp. (Adults) & 19.293 \\
Resp. (Older Adults) & 20.526 \\
Resp. (Minors) & 17.135 \\
Cardio. (All) & 21.084 \\
Cardio. (Adults) & 21.354 \\
Cardio. (Older Adults) & 20.611 \\
Cardio. (Minors) & 17.726 \\
Resp. (All, 3-Day Rolling Sum) & 17.088 \\
Resp. (Adults, 3-Day Rolling Sum) & 18.185 \\
Resp. (Older Adults, 3-Day Rolling Sum) & 22.185 \\
Resp. (Minors, 3-Day Rolling Sum) & 17.466 \\
Cardio. (All, 3-Day Rolling Sum) & 28.363 \\
Cardio. (Adults, 3-Day Rolling Sum) & 24.260 \\
Cardio. (Older Adults, 3-Day Rolling Sum) & 34.249 \\
Cardio. (Minors, 3-Day Rolling Sum) & 18.898 \\
\hline
\end{tabular}

Notes: This table reports "optimal" bandwidths for different dependent variables, computed using methods from Calonico, Cattaneo and Titiunik (2014 2015). 
Table A6-Analysis of Dynamic EFFects with DifFerent Bandwidths

\begin{tabular}{ccccc}
\hline \hline & \multicolumn{4}{c}{ Age Groups } \\
\cline { 2 - 5 } & $\begin{array}{c}\text { Minors } \\
(0-19)\end{array}$ & $\begin{array}{c}\text { Adults } \\
(20-64)\end{array}$ & $\begin{array}{c}\text { Older } \\
\text { Adults } \\
(65+)\end{array}$ & All \\
Respiratory Illness & & & & \\
\cline { 3 - 5 } Sample Modification & & & & \\
\cline { 1 - 5 } Bandwidth: 16 & -32.087 & -10.266 & -11.953 & -14.688 \\
& $(10.967)$ & $(4.058)$ & $(5.892)$ & $(5.065)$ \\
Bandwidth: 20 & -38.220 & -10.703 & -12.977 & -16.125 \\
& $(13.769)$ & $(4.662)$ & $(6.624)$ & $(5.935)$ \\
Bandwidth: 24 & -32.998 & -7.851 & -8.139 & -12.693 \\
& $(13.702)$ & $(4.715)$ & $(6.878)$ & $(5.882)$ \\
\hline
\end{tabular}

\section{Cardiovascular Illness}

\begin{tabular}{|c|c|c|c|c|}
\hline Sample Modification & & & & \\
\hline Bandwidth: 16 & $\begin{array}{l}-0.146 \\
(0.089)\end{array}$ & $\begin{array}{l}-4.796 \\
(1.682)\end{array}$ & $\begin{array}{l}-25.911 \\
(12.085)\end{array}$ & $\begin{array}{l}-7.034 \\
(2.533)\end{array}$ \\
\hline Bandwidth: 20 & $\begin{array}{c}-0.064 \\
(0.075)\end{array}$ & $\begin{array}{l}-5.279 \\
(1.993)\end{array}$ & $\begin{array}{c}-30.388 \\
(12.987)\end{array}$ & $\begin{array}{l}-8.042 \\
(3.057)\end{array}$ \\
\hline Bandwidth: 24 & $\begin{array}{c}0.007 \\
(0.076)\end{array}$ & $\begin{array}{l}-3.785 \\
(2.059)\end{array}$ & $\begin{array}{l}-26.687 \\
(12.366)\end{array}$ & $\begin{array}{l}-6.718 \\
(3.081)\end{array}$ \\
\hline
\end{tabular}

$\mathrm{N}$

Bandwidth 16: 1,857

Bandwidth 20: 2,530

Bandwidth 24: 3,380

\footnotetext{
Notes: This table reports results from 24 2SLS local-linear regressions with varying bandwidths $(16$, 20, or $24)$. The dependent variable in all regressions is three-day respiratory or cardiovascular disease expenditures (from day $t$ to day $t+2$ ) for the relevant age group, measured in cents per capita (11.5 KRW $=0.01 \mathrm{USD}$ ), and the independent variable of interest is an advisory indicator. All regressions control for the running variable, an interaction between the running variable and the indicator for the running variable being above the RD threshold, temperature, precipitation, and year-by-month and day-of-week fixed effects. The level of observation is the district by day, and observations are population weighted. Parentheses contain standard errors clustered by day of sample.
} 
Table A7-Robustness Check - Exclusion of Later Alert Days And Removal of EARly/Late Alerts

\begin{tabular}{ccccc}
\hline \hline & \multicolumn{4}{c}{ Age Groups } \\
\cline { 2 - 5 } & $\begin{array}{c}\text { Minors } \\
(0-19)\end{array}$ & $\begin{array}{c}\text { Adults } \\
(20-64)\end{array}$ & $\begin{array}{c}\text { Older } \\
\text { Adults } \\
(65+)\end{array}$ & All \\
Respiratory Illness & & & & \\
\cline { 4 - 5 } Sample Modification & & & & \\
\cline { 3 - 5 } Without Later & -13.622 & -1.563 & -1.229 & -3.579 \\
Alert Days & $(6.692)$ & $(1.290)$ & $(1.396)$ & $(2.006)$ \\
Without Later & -13.213 & -3.412 & -3.812 & -5.219 \\
Alert Days of RV $<0$ & $(4.678)$ & $(1.855)$ & $(2.432)$ & $(2.174)$ \\
Without & -16.274 & -4.093 & -4.687 & -6.320 \\
9PM-6AM & $(6.248)$ & $(2.268)$ & $(2.996)$ & $(2.675)$ \\
Without & -17.759 & -4.428 & -5.113 & -6.856 \\
8PM-8AM & $(6.908)$ & $(2.451)$ & $(3.281)$ & $(2.918)$ \\
\hline
\end{tabular}

\section{Cardiovascular Illness}

\begin{tabular}{cccccc}
\hline Sample Modification & & & & \\
\cline { 1 - 1 } Without Later & & -0.025 & -2.056 & -8.425 & -2.237 \\
Alert Days & $(0.045)$ & $(0.746)$ & $(3.484)$ & $(0.896)$ \\
& & & & \\
Without Later & -0.036 & -2.387 & -8.204 & -2.723 \\
Alert Days of RV $<0$ & $(0.030)$ & $(0.619)$ & $(2.897)$ & $(0.815)$ \\
Without & -0.043 & -3.064 & -10.502 & -3.533 \\
9PM-6AM & $(0.038)$ & $(0.834)$ & $(4.012)$ & $(1.091)$ \\
Without & -0.047 & -3.315 & -11.457 & -3.833 \\
8PM-8AM & $(0.041)$ & $(0.924)$ & $(4.495)$ & $(1.218)$ \\
\hline
\end{tabular}

Notes: This table reports results from 32 2SLS local-linear regressions. The dependent variable in all regressions is respiratory or cardiovascular disease expenditures for the relevant age group, measured in cents per capita $(11.5 \mathrm{KRW}=0.01 \mathrm{USD})$, and the independent variable of interest is an advisory indicator. All regressions control for the running variable, an interaction between the running variable and the indicator for the running variable being above the RD threshold, temperature, precipitation, and year-by-month and day-of-week fixed effects. The level of observation is the district by day, and observations are population weighted. Parentheses contain standard errors clustered by day of sample. The bandwidth is set to 20 in all regressions. In each panel, the first excludes alert days following the first day of an air quality alert, and the second row excludes alert days on which the running variable falls below zero. The third row excludes days on which the alert was cancelled before 6 am or triggered after 9 pm, while the fourth row excludes days on which the alert was cancelled before 8 am or triggered after 8 pm. 
TABLE A8-FRD COEFFICIENTS WITH DIFFERENT SPECIFICATIONS

\begin{tabular}{|c|c|c|c|c|}
\hline \multirow[b]{2}{*}{ Respiratory Illness } & \multicolumn{4}{|c|}{ Age Groups } \\
\hline & $\begin{array}{c}\text { Minors } \\
(0-19)\end{array}$ & $\begin{array}{l}\text { Adults } \\
(20-64)\end{array}$ & $\begin{array}{c}\text { Older } \\
\text { Adults } \\
(65+)\end{array}$ & All \\
\hline \multicolumn{5}{|l|}{ Specification Modification } \\
\hline Quadratic RV & $\begin{array}{l}-18.220 \\
(11.167)\end{array}$ & $\begin{array}{l}-7.586 \\
(3.221)\end{array}$ & $\begin{array}{l}-7.718 \\
(4.404)\end{array}$ & $\begin{array}{l}-9.607 \\
(4.337)\end{array}$ \\
\hline Quadratic Temperature & $\begin{array}{c}-15.611 \\
(5.710)\end{array}$ & $\begin{array}{l}-4.064 \\
(2.105)\end{array}$ & $\begin{array}{l}-4.569 \\
(2.808)\end{array}$ & $\begin{array}{l}-6.167 \\
(2.499)\end{array}$ \\
\hline Alternative Time FE & $\begin{array}{c}-14.502 \\
(5.698)\end{array}$ & $\begin{array}{l}-2.982 \\
(2.152)\end{array}$ & $\begin{array}{l}-3.274 \\
(2.858)\end{array}$ & $\begin{array}{l}-5.045 \\
(2.495)\end{array}$ \\
\hline \multicolumn{5}{|l|}{ Cardiovascular Illness } \\
\hline \multicolumn{5}{|l|}{ Specification Modification } \\
\hline Quadratic RV & $\begin{array}{l}-0.028 \\
(0.074)\end{array}$ & $\begin{array}{l}-4.611 \\
(1.487)\end{array}$ & $\begin{array}{c}-14.329 \\
(6.994)\end{array}$ & $\begin{array}{l}-5.138 \\
(1.714)\end{array}$ \\
\hline Quadratic Temperature & $\begin{array}{l}-0.039 \\
(0.035)\end{array}$ & $\begin{array}{l}-2.702 \\
(0.776)\end{array}$ & $\begin{array}{l}-9.022 \\
(3.607)\end{array}$ & $\begin{array}{l}-3.126 \\
(1.020)\end{array}$ \\
\hline Alternative Time FE & $\begin{array}{l}-0.041 \\
(0.034)\end{array}$ & $\begin{array}{l}-2.650 \\
(0.760)\end{array}$ & $\begin{array}{l}-9.286 \\
(3.561)\end{array}$ & $\begin{array}{l}-3.128 \\
(0.983)\end{array}$ \\
\hline
\end{tabular}

Notes: This table reports results from 24 2SLS local-linear regressions. The dependent variable in all regressions is respiratory or cardiovascular disease expenditures for the relevant age group, measured in cents per capita (11.5 $\mathrm{KRW}=0.01 \mathrm{USD}$ ), and the independent variable of interest is an advisory indicator. All regressions control for the running variable, an interaction between the running variable and the indicator for the running variable being above the RD threshold, temperature, precipitation, and year-by-month and day-of-week fixed effects. The first, second, and third rows in each panel add controls for a quadratic in the running variable, a quadratic in temperature, and year and month fixed effects (instead of year-by-month fixed effects) respectively. The level of observation is the district by day, and observations are population weighted. Parentheses (square brackets) contain standard errors clustered by the running variable (day of sample). The bandwidth is set to 20 in all regressions. 
Table A9-Robustness Check - Addition of Air Pollution Covariates

\begin{tabular}{ccccc}
\hline \hline & \multicolumn{4}{c}{ Age Groups } \\
\cline { 2 - 5 } & $\begin{array}{c}\text { Minors } \\
(0-19)\end{array}$ & $\begin{array}{c}\text { Adults } \\
(20-64)\end{array}$ & $\begin{array}{c}\text { Older } \\
\text { Adults } \\
(65+)\end{array}$ & All \\
Respiratory Illness & & & & \\
\cline { 3 - 5 } Added Covariates & & & -3.860 & -5.379 \\
\cline { 1 - 4 } PM10 & -14.665 & -3.294 & $(2.507)$ & $(2.253)$ \\
& $(5.249)$ & $(1.912)$ & -4.033 & -5.486 \\
PM2.5 & -14.232 & -3.558 & $(2.536)$ & $(2.274)$ \\
& $(5.117)$ & $(1.970)$ & -3.849 & -5.353 \\
PM10 \& PM2.5 & -14.531 & -3.296 & $(2.491)$ & $(2.230)$ \\
& $(5.100)$ & $(1.902)$ & -3.863 & -5.510 \\
AQI & -14.626 & -3.489 & $(2.589)$ & $(2.300)$ \\
\hline
\end{tabular}

\section{Cardiovascular Illness}

\begin{tabular}{|c|c|c|c|c|}
\hline \multicolumn{5}{|l|}{ Added Covariates } \\
\hline \multirow[b]{3}{*}{ PM10 \& PM2.5 } & $\begin{array}{c}-0.036 \\
(0.037)\end{array}$ & $\begin{array}{c}-2.654 \\
(0.733)\end{array}$ & $\begin{array}{l}-8.957 \\
(3.537)\end{array}$ & $\begin{array}{l}-3.076 \\
(0.948)\end{array}$ \\
\hline & $\begin{array}{l}-0.045 \\
(0.035)\end{array}$ & $\begin{array}{l}-2.790 \\
(0.733)\end{array}$ & $\begin{array}{l}-9.510 \\
(3.529)\end{array}$ & $\begin{array}{c}-3.174 \\
(0.945)\end{array}$ \\
\hline & $\begin{array}{l}-0.037 \\
(0.036)\end{array}$ & $\begin{array}{c}-2.663 \\
(0.731)\end{array}$ & $\begin{array}{l}-8.995 \\
(3.545)\end{array}$ & $\begin{array}{c}-3.076 \\
(0.942)\end{array}$ \\
\hline AQI & $\begin{array}{l}-0.027 \\
(0.038)\end{array}$ & $\begin{array}{l}-2.760 \\
(0.755)\end{array}$ & $\begin{array}{c}-8.890 \\
(3.502)\end{array}$ & $\begin{array}{c}-3.080 \\
(0.956)\end{array}$ \\
\hline \multicolumn{5}{|c|}{$\begin{array}{l}\text { Notes: This table reports results from } 32 \text { 2SLS local-linear regressions. The dependent variable in all re- } \\
\text { gressions is respiratory or cardiovascular disease expenditures for the relevant age group, measured in cents } \\
\text { per capita ( } 11.5 \mathrm{KRW}=0.01 \mathrm{USD} \text { ), and the independent variable of interest is an advisory indicator. All } \\
\text { regressions control for the running variable, an interaction between the running variable and the indicator } \\
\text { for the running variable being above the RD threshold, temperature, precipitation, and year-by-month and } \\
\text { day-of-week fixed effects. The first, second, third, and fourth rows in each panel add controls for PM10, } \\
\text { PM2.5, both PM10 and PM2.5, and the AQI, respectively (averaged across the day). The level of observa- } \\
\text { tion is the district by day, and observations are population weighted. Parentheses contain standard errors } \\
\text { clustered by day of sample. The bandwidth is set to } 20 \text { in all regressions. }\end{array}$} \\
\hline
\end{tabular}


TABlE A10-Robustness CHECK - STANDARD ERrors With DifFEREnT Clusters

\begin{tabular}{|c|c|c|c|c|}
\hline \multirow[b]{2}{*}{ Respiratory Illness } & \multicolumn{4}{|c|}{ Age Groups } \\
\hline & $\begin{array}{c}\text { Minors } \\
(0-19)\end{array}$ & $\begin{array}{l}\text { Adults } \\
(20-64)\end{array}$ & $\begin{array}{c}\text { Older } \\
\text { Adults } \\
(65+)\end{array}$ & All \\
\hline FRD Coefficient & -15.033 & -3.777 & -4.303 & -5.829 \\
\hline \multicolumn{5}{|l|}{ Clustering Level } \\
\hline Province by Day of Week & $(5.345)$ & $(1.568)$ & $(1.953)$ & $(1.938)$ \\
\hline Province by Day of Sample & $(6.114)$ & $(2.140)$ & $(2.621)$ & $(2.524)$ \\
\hline Region by Day of Week & $(5.217)$ & $(1.497)$ & $(1.929)$ & $(1.880)$ \\
\hline Region by Day of Sample & $(6.081)$ & $(2.110)$ & $(2.592)$ & $(2.490)$ \\
\hline District by Day of Week & $(1.828)$ & $(0.645)$ & $(1.171)$ & $(0.751)$ \\
\hline District & $(2.077)$ & $(0.886)$ & $(1.010)$ & $(1.014)$ \\
\hline \multicolumn{5}{|l|}{ Cardiovascular Illness } \\
\hline FRD Coefficient & -0.040 & -2.828 & -9.641 & -3.259 \\
\hline \multicolumn{5}{|l|}{ Clustering Level } \\
\hline Province by Day of Week & $(0.042)$ & $(0.954)$ & (4.199) & $(1.253)$ \\
\hline Province by Day of Sample & $(0.038)$ & $(0.834)$ & $(3.742)$ & $(1.033)$ \\
\hline Region by Day of Week & $(0.042)$ & $(0.923)$ & $(3.966)$ & $(1.209)$ \\
\hline Region by Day of Sample & $(0.038)$ & $(0.813)$ & $(3.607)$ & $(1.001)$ \\
\hline District by Day of Week & $(0.039)$ & $(0.462)$ & $(2.645)$ & $(0.569)$ \\
\hline District & $(0.036)$ & $(0.518)$ & $(2.336)$ & $(0.540)$ \\
\hline
\end{tabular}

Notes: This table reports different standard errors for eight 2SLS local-linear regressions. The dependent variable in all regressions is respiratory or cardiovascular disease expenditures for the relevant age group, measured in cents per capita $(11.5 \mathrm{KRW}=0.01 \mathrm{USD})$, and the independent variable of interest is an advisory indicator. All regressions control for the running variable, an interaction between the running variable and the indicator for the running variable being above the RD threshold, temperature, precipitation, and year-by-month and day-of-week fixed effects. The level of observation is the district by day, and observations are population weighted. In each panel parentheses contain standard errors clustered by province by day-of-week (second row), province by day-of-sample (third row), region by day-of-week (fourth row), region by day-of-sample (fifth row), district by day-of-week (sixth row), and district (seventh row). The bandwidth is set to 20 in all regressions. 
TABle A11-Robustness Check - Spillover Effect and Falsification Tests

\begin{tabular}{ccccc}
\hline \hline & \multicolumn{4}{c}{ Age Groups } \\
\cline { 2 - 5 } & $\begin{array}{c}\text { Minors } \\
(0-19)\end{array}$ & $\begin{array}{c}\text { Adults } \\
(20-64)\end{array}$ & $\begin{array}{c}\text { Older } \\
\text { Adults } \\
(65+)\end{array}$ & All \\
& & & & \\
Respiratory Illness & & & & \\
Specification Modification & -0.029 & 0.217 & 0.453 & 0.147 \\
Spillover & $(4.658)$ & $(1.180)$ & $(1.778)$ & $(1.743)$ \\
& 0.381 & 0.296 & 0.832 & 0.334 \\
Falsification (-20) & $(1.528)$ & $(0.478)$ & $(0.792)$ & $(0.634)$ \\
Falsification $(-30)$ & 1.424 & 0.036 & -0.186 & 0.286 \\
Falsification $(-50)$ & $(1.023)$ & $(0.333)$ & $(0.520)$ & $(0.430)$ \\
& -0.658 & -0.335 & -0.391 & -0.400 \\
& $(0.715)$ & $(0.232)$ & $(0.358)$ & $(0.310)$ \\
\hline
\end{tabular}

\section{Cardiovascular Illness}

\begin{tabular}{|c|c|c|c|c|}
\hline Specification Modification & & & & \\
\hline Spillover & $\begin{array}{c}0.029 \\
(0.023)\end{array}$ & $\begin{array}{c}0.295 \\
(0.809)\end{array}$ & $\begin{array}{l}-1.054 \\
(4.547)\end{array}$ & $\begin{array}{c}0.074 \\
(1.067)\end{array}$ \\
\hline Falsification $(-20)$ & $\begin{array}{c}0.007 \\
(0.025)\end{array}$ & $\begin{array}{c}-0.062 \\
(0.340)\end{array}$ & $\begin{array}{l}-0.458 \\
(1.951)\end{array}$ & $\begin{array}{l}-0.037 \\
(0.461)\end{array}$ \\
\hline Falsification $(-30)$ & $\begin{array}{l}-0.046 \\
(0.017)\end{array}$ & $\begin{array}{l}-0.072 \\
(0.257)\end{array}$ & $\begin{array}{c}-0.923 \\
(1.656)\end{array}$ & $\begin{array}{l}-0.206 \\
(0.380)\end{array}$ \\
\hline Falsification $(-50)$ & $\begin{array}{l}-0.014 \\
(0.009)\end{array}$ & $\begin{array}{c}0.102 \\
(0.131)\end{array}$ & $\begin{array}{c}1.226 \\
(0.821)\end{array}$ & $\begin{array}{c}0.197 \\
(0.193)\end{array}$ \\
\hline
\end{tabular}

Notes: This table reports results from 32 2SLS local-linear regressions. The dependent variable in all regressions is respiratory or cardiovascular disease expenditures for the relevant age group, measured in cents per capita (11.5 KRW $=0.01$ USD), and the independent variable of interest is an advisory indicator, which is shifted either geographically or generated by shifting the running variable by a constant. In each panel, the first row shifts the advisory indicator to correspond to an advisory in the nearest alert region to region $i$. The second, third, and fourth rows use an advisory indicator that is generated after shifting the running variable downwards by 20,30 , or 50 units respectively. All regressions control for the running variable, an interaction between the running variable and the indicator for the running variable being above the RD threshold, temperature, precipitation, and year-by-month and day-of-week fixed effects. The level of observation is the district by day, and observations are population weighted. Parentheses contain standard errors clustered by day of sample. The bandwidth is set to 20 in all regressions. 
TABLE A12-LIST OF BUDGET ITEMS RELATED TO ALERT SYSTEM

\begin{tabular}{|c|c|}
\hline City & Item \\
\hline Gwangju & Air Pollution Monitor - Electricity Cost \\
\hline Gwangju & Line Rental for Air Quality Warning System \\
\hline Gwangju & Air Pollution Monitor Management Cost (General) \\
\hline Gwangju & Air Pollution Monitor - Automatic Control System \\
\hline Gwangju & Air Pollution Monitor Alert System \\
\hline Daejeon & Advertisement - Electronic Board Fee \\
\hline Daejeon & Line Rental for Air Pollution Management System \\
\hline Daejeon & Air Pollution Management System - Maintenance Cost \\
\hline Daejeon & Air Pollution Management System - Establishment Cost \\
\hline Daejeon & Air Pollution Monitor - Installation Cost \\
\hline Daegu & Line Rental for Air Quality Warning System \\
\hline Daegu & Air Pollution Alert System - Maintenance Cost \\
\hline Busan & Air Pollution Monitor - Maintenance Cost \\
\hline Busan & Air Pollution Monitor Data Collecting Machine - Maintenance Cost \\
\hline Busan & Air Pollution Monitor - Battery Change \\
\hline Busan & Indoor Air Quality Monitor - Maintenance Cost \\
\hline Busan & Indoor Air Quality Monitor Data Collecting Machine - Maintenance Cost \\
\hline Busan & Air Pollution Alert System - Maintenance Cost \\
\hline Busan & Sampling \& Analysis Equipment - Maintenance Cost \\
\hline Busan & Air Pollution Monitor - Maintenance Cost \\
\hline Busan & Indoor Air Quality Monitor - Maintenance Cost \\
\hline Busan & Air Pollution Monitor - Electronic Board Maintenance Cost \\
\hline Seoul & Air Pollution Information System - Office Management Cost \\
\hline Seoul & Air Pollution Information System - Maintenance Cost \\
\hline Seoul & Air Pollution Information System - SMS Service \\
\hline Seoul & Air Quality Modeling System Construction \\
\hline Seoul & Air Quality Evaluation Program Development \\
\hline Seoul & Air Quality Real-Time Information Provision System Construction \\
\hline Seoul & Air Pollution Information System - IT Development \\
\hline Seoul & Ambient Air Quality Situation Room Construction \\
\hline Seoul & Ambient Air Quality Information Service Infrastructure \\
\hline Seoul & Air Quality Information System - Supervision \\
\hline Seoul & Air Pollution Information System - IT Solution \& Planning Development \\
\hline Ulsan & Advertisement - Electronic Board Fee \\
\hline Ulsan & Air Pollution Monitor - Electricity Cost \\
\hline Ulsan & Line Rental for Air Pollution Monitor \\
\hline Ulsan & Ambient Air Quality Situation Room - Maintenance Cost \\
\hline Ulsan & Air Pollution Monitor - Outsourcing Maintenance Cost \\
\hline Ulsan & Air Pollution Monitor Equipment - Maintenance Cost \\
\hline Ulsan & Air Pollution Monitor - Maintenance Cost \\
\hline Ulsan & Environmental Measurement Equipment Inspection Cost \\
\hline Ulsan & Air Pollution Monitor - Battery Change \\
\hline Incheon & Air Pollution Monitoring - Public Cost \\
\hline Incheon & Air Pollution Monitoring - Equipment Maintenance Cost \\
\hline Incheon & Environmental Measurement Equipment Inspection Cost \\
\hline Incheon & Air Pollution Monitor - Movement Cost \\
\hline Incheon & Air Pollution Monitor - Outsourcing Maintenance Cost \\
\hline Incheon & Environment Automatic Monitoring System - Outsourcing Maintenance Cost \\
\hline Incheon & Air Pollution Monitor Network Establishment \\
\hline
\end{tabular}

Notes: Each row reports an item related to the alert system in each city. 


\begin{tabular}{ccc}
\hline \hline City & Cost [USD, 2017] & Cost [USD, 2018] \\
\hline Gwangju & 190,751 & 192,317 \\
Daejeon & 151,530 & 190,887 \\
Daegu & 293,925 & 309,012 \\
Busan & 375,257 & 471,538 \\
Seoul & 187,879 & 634,157 \\
Ulsan & 329,588 & 464,695 \\
Incheon & 485,627 & 571,334 \\
\hline Toal & $2,014,558$ & $2,833,940$ \\
\hline
\end{tabular}

Notes: Each row reports the system management cost of air quality alerts in the seven major cities in the sample. 